\title{
TECTONIC STRESS FIELD AT INTERMEDIATE DEPTHS OF THE SOUTHERN FLANK OF THE KURIL-KAMCHATKA SEISMIC ZONE
}

\section{D.A. Safonov ${ }^{凶}$}

Institute of Marine Geology and Geophysics, Far Eastern Branch of the Russian Academy of Sciences, 1b Nauki St, Yuzhno-Sakhalinsk 693022, Russia

ABSTRACT. The study has been done on the field of the principal tectonic stresses direction at intermediate depths of earthquakes of the southern flank of the Kuril-Kamchatka subduction system separately for the upper and lower double seismic focal zones. Use has been made of the NIED and GlobalCMT catalogue data. The computation-based results are presented on schemes of the stressed state of the investigated areas and in tables. In the context of the southern Kuril Islands, evidence has been provided for predominance of the maximum compressive stresses along the slab plane in the upper layer and minimal compressive stresses (deviatoric extension) in the lower layer. However, the principal axes of maximum and minimum compression are displaced in direction relative to the slab dip: by $30-40^{\circ}$ counterclockwise for the compression axis in the upper layer, which coincides with the direction of plate movement, and clockwise for the extension axis in the lower layer. This might be caused by the right-lateral strike-slip component of the Pacific Plate subduction. Unlike the general trend, the orientation of the principal axes of the stress field beneath the central Hokkaido-related segments in the upper layer is almost identical to that in the lower layer. There have also been found the segments exposed to shear stress, with the most extensive located opposite the northern Kunashir Island and beneath the southern Hokkaido Island. The results obtained for major large groups of clusters show good accordance with those published by other authors. The discrepancies relate primarily to small groups of isolated clusters showing local stress field heterogeneities.

KEYWORDS: Kuril-Okhotsk region; double seismic focal zone; tectonic stress field; slab; intermediate depth

FUNDING: The research was carried out within the state assignment of Ministry of Science and Higher Education of the Russian Federation (theme No. 121022000085-9).

\section{RESEARCH ARTICLE}

Correspondence: Dmitry A. Safonov, d.safonov@imgg.ru
Received: December 17, 2020

Revised: June 9, 2021

Accepted: June 14, 2021

FOR CITATION: Safonov D.A., 2021. Tectonic stress field at intermediate depths of the southern flank of the Kuril-Kamchatka seismic zone. Geodynamics \& Tectonophysics 12 (4), 929-950. doi:10.5800/GT-2021-12-4-0564 


\title{
ПОЛЕ ТЕКТОНИЧЕСКИХ НАПРЯЖЕНИЙ НА ПРОМЕЖУТОЧНЫХ ГЛУБИНАХ ЮЖНОГО ФЛАНГА КУРИЛО-КАМЧАТСКОЙ СЕЙСМОФОКАЛЬНОЙ ЗОНЫ
}

\author{
Д.А. Сафонов
}

Институт морской геологии и геофизики ДВО РАН, 693022, Южно-Сахалинск, ул. Науки, 1Б, Россия

АННОТАЦИЯ. Исследовано поле ориентаций осей главных тектонических напряжений на участке промежуточных глубин землетрясений южного фланга Курило-Камчатской субдукционной системы отдельно для верхнего и нижнего слоя двойной сейсмофокальной зоны. Привлечены данные каталогов NIED и GlobalCMT. Результаты расчетов представлены в виде схем напряженного состояния изучаемых областей и таблиц. Для района южных Курильских островов подтверждено преобладание направления напряжений наибольшего сжатия вдоль плоскости слэба в верхнем слое и наименьшего сжатия (девиаторного растяжения) в нижнем. Однако направление главных осей наибольшего и наименьшего сжатия смещено относительно направления падения слэба: против часовой стрелки на $30-40^{\circ}$ для оси сжатия в верхнем слое, что совпадает с направлением движения плиты, по часовой стрелке для оси растяжения в нижнем слое. Это может являться следствием правосторонней сдвиговой компоненты в поддвиге Тихоокеанской плиты. В отличие от общей закономерности, по ориентации главных осей поле напряжений под центральной частью сегментов, относящихся к о. Хоккайдо, в верхнем слое практически идентично нижнему слою. Также выявлены участки, находящиеся в условиях сдвиговых напряжений, самые протяженные напротив северной части о. Кунашир и под южной частью о. Хоккайдо. Показано хорошее соответствие результатов для основных крупных групп кластеров данным других авторов. Расхождения в первую очередь касаются небольших групп обособленных кластеров, показывающих локальные неоднородности поля напряжений.

КЛЮЧЕВЫЕ СЛОВА: Курило-Охотский регион; двойная сейсмофокальная зона; поле тектонических напряжений; слэб; промежуточные глубины

ФИНАНСИРОВАНИЕ: Работа выполнена в рамках государственного задания Министерства науки и высшего образования Российской Федерации (тема № 121022000085-9).

\section{1. ВВЕДЕНИЕ}

Курило-Камчатская субдукционная система удобна для изучения, поскольку сейсмичность здесь представлена землетрясениями всего диапазона глубин от сильных преджелобных событий сбросового типа на изгибе океанской плиты до не менее сильных сверхглубоких землетрясений вблизи границы переходного слоя с нижней мантией. По сравнению с некоторыми другими субдукционными системами, поверхность плиты (слэба) относительно равномерно погружается под Охотское море. Неплохо выдерживается направление и угол падения с учетом изгиба системы дуга - желоб и выполаживания к юго-западу [Hayes et al., 2018]. Вдоль падения слэба в его верхней сейсмоактивной части отмечаются параллельные желобу область преддугового растяжения океанической плиты, наиболее активная область контакта литосферных плит, расположенная ниже по падению область внутриплитовых событий промежуточной глубины, ограниченная слоем сейсмического затишья (seismic gap). Нижерасположенные сейсмогенерирующие участки, как считается, привязаны к областям фазовых переходов. В данной работе будет рассмотрен южный фланг Курило-Камчатской субдукционной системы на участке промежуточных (средних, intermediate) глубин землетрясений.

Землетрясения на промежуточных глубинах, в отличие от участков меньшей глубины, обусловлены не непосредственно межплитовым взаимодействием, а тектоническими процессами в верхней части погружающейся в мантию океанической литосферной плиты. Есть различные взгляды на природу этих землетрясений. Согласно одной из наиболее распространенных гипотез, причиной может служить обратный изгиб слэба в пластичном мантийном веществе, освобожденном от давления зоны контакта литосферных плит [Astiz et al., 1988; Jiao et al., 2000]. Океаническая плита, столкнувшись с более легкой и толстой плитой окраинного моря (в случае Курило-Камчатской субдукционной системы), изгибается, погружаясь под углом, увеличивающимся от $18^{\circ}$ непосредственно под глубоководным желобом до 30-50 под островной дугой. После прохождения зоны контакта плит происходит обратный процесс разгибания плиты, сопровождающийся сжатием ее верхней части и растяжением более глубоких упругих слоев с возникновением небольшого асейсмичного промежутка между ними, что подтверждается распределением сейсмодислокаций происходящих здесь землетрясений. Подобный механизм объясняет образование двухслойной структуры сейсмофокальной зоны в области промежуточных глубин в большинстве субдукционных систем, например Курило-Камчатской, двойная структура которой обнаружена одной из первых [Sykes, 1966] и описана в различных источниках [Hasegawa et al., 1978; Katsumata et al., 2003; и др.]. Двойная сейсмофокальная зона с 
изменением ориентации осей главных напряжений на $90^{\circ}$ (переиндексацией главных напряжений) на средних глубинах характерна для старых и быстро погружающихся участков плит, таких как в Японской и Курило-Камчатской субдукционных системах [Fujita, Kanamori, 1981; Kirby et al., 1991]. Также она обнаружена в районе Новой Зеландии, под Центральной Америкой, Южной Италией.

Изменение ориентации главных напряжений на средних глубинах может объясняться открытием или закрытием зоны контакта литосферных плит в зависимости от фазы подготовки крупных межплитовых землетрясений [Astiz et al., 1988; Lay et al., 2011]. Это явление наблюдалось при нескольких сильных землетрясениях на Алеутах в 1957 г., в Чили в 1960 г. и на Курилах в 1963 г. [Lay et al., 2011]. Такое объяснение может не противоречить вышеприведенной модели обратного изгиба, если допустить молчание одного из двух слоев в результате отсутствия или, наоборот, избыточного накопления напряжений при активизации подвижек в верхней части слэба. Примером активизации промежуточных глубин после межплитовых событий может послужить Урупская серия землетрясений, произошедших в изучаемом районе в 2012-2013 гг. [Safonov et al., 2015].

Причиной либо механизмом, делающим принципиально возможными землетрясения на промежуточных глубинах, часто также указывают дегидратацию. Перед вхождением в зону субдукции океаническая кора испытывает растяжение, зоны трещиноватости становятся водопроницаемыми. В результате метаморфизма образуется широкий спектр водосодержащих минералов. При погружении в области высоких давлений и температур водные флюиды высвобождаются, проникая вверх сквозь толщу мантийных пород и вдоль слэба, создавая слой с высоким градиентом давления [Kirby et al., 1991; Seliverstov, 2007; Faccenda et al., 2012; Rodkin, Rundkvist, 2017]. Эта термомеханическая модель также может не конкурировать, а дополнять другие предполагаемые механизмы образования двойной сейсмофокальной зоны, связывая области сейсмичности с участками дегидратации пород. Детальный обзор имеющихся гипотез, объясняющих процессы в зоне промежуточных глубин, приведен в работе [Chen et al., 2004].

Промежуточным традиционно называется диапазон глубин 70-300 км [Fujita, Kanamori, 1981; Kirby et al., 1991; и др.]. Однако область контакта литосферных плит может заканчиваться существенно выше. Так, в работе [Prytkov et al., 2017] модельные оценки глубины контакта литосферных плит для Южных Курил указаны в диапазоне 44-62 км, а в работе [Seliverstov, 2007] при рассмотрении двойной зоны субдукции северного фланга дуги указаны глубины 50-200 км. В связи с этим в данной работе будут рассмотрены участки слэба начиная с глубины в 50 км, чтобы захватить возможные районы, в которых напряжения все еще обусловлены межплитовым взаимодействием, но при этом исключить более высокие участки слэба, погружающиеся под меньшими углами.

Нижняя граница зоны промежуточных глубин определяется постепенным затуханием сейсмичности. В данной работе будут рассматриваться каталоги землетрясений до глубин в 250 км, хотя, как будет показано, необходимое для анализа количество землетрясений заканчивается на меньших глубинах.

Сейсмичность и система тектонических напряжений в районе южного фланга Курило-Камчатской субдукционной системы неплохо изучена [Hasegawa et al., 1978; Katsumata et al., 2003; Boriskina et al., 2019; и др.], в том числе методами инверсии механизмов очагов землетрясений [Terakawa, Matsu'ura, 2010; Rebetsky, Polec, 2014; Christova, 2015].

Вероятно, по причине избытка качественных данных, много работ посвящены сегменту Хоккайдо и зоне сочленения Курило-Камчатской и Японской субдукционных систем [Christova, Tsapanos, 2000; Katsumata et al., 2003; Christova et al., 2006; Ghimire, Kasahara, 2009; и др.]. В частности, здесь показан сложный характер взаимодействия соседних субдукционных систем: поддвиг Хоккайдского сегмента Курило-Камчатской зоны субдукции под сегмент Тохоку с вероятным образованием на погруженной части плиты под территорией Хоккайдо почти вертикального среза (Tokachi-Oki slabcracking zone) [Katsumata et al., 2003].

Интересно проследить вертикальные субпараллельные разломные структуры трансформного типа Носаппу, Итуруп [Kasahara et al., 1997] и Уруп [Boriskina et al., 2019], которые вместе с Тихоокеанской плитой погружаются в мантию и, как предполагается, могут оставаться активными до больших глубин. Возможно, с подвижками по трансформным разломам связаны некоторые землетрясения с механизмом очага типа левого сдвига вдоль падения, такие как наиболее сильное за последние полвека событие 6 декабря 1978 г. с магнитудой $M_{w}=7.8$, произошедшее на глубине около 160-180 км (по разным источникам) в районе Южных Курил.

В работах [Terakawa, Matsu'ura, 2010; Rebetsky, Polets, 2014], несмотря на детальное описание поля тектонических напряжений региона (в основном Японии, но с захватом части Южных Курил) вдоль поверхности, двойная структура сейсмофокальной зоны подробно не рассматривается. В статье [Zlobin et al., 2011] авторы (включая автора представляемой работы) проанализировали сейсмичность и систему тектонических напряжений внутри курильской части сейсмофокальной зоны по данным каталога механизмов очагов землетрясений [Poplavskaya et al., 2011], однако ввиду малого количества данных двойная структура сейсмофокальной зоны на промежуточных глубинах также не рассматривалась.

Наиболее детальный анализ системы тектонических напряжений вдоль Курильской дуги на всем диапазоне глубин, включая двойную сейсмофокальную зону на промежуточных глубинах, приведен в работах 
[Christova, Tsapanos, 2000; Christova et al., 2006; Christova, 2015]. Использовался метод инверсии GF84 [Gephart, Forsyth, 1984], данные о тензорах сейсмического момента по каталогу GlobalCMT [Global CMT Catalog, 2020] и из некоторых дополнительных источников. В работе [Christova et al., 2006] использовались данные японских каталогов. Район исследования поделен на 13 сегментов для Курильской дуги и 11 сегментов для Хоккайдо и северной части Хонсю. В каждом из них осуществлялись выборки землетрясений на основе взаимного расположения гипоцентров и ориентации осей напряжений в механизмах очагов отдельных событий относительно слэба. В результате получены оценки ориентации главных осей поля тектонических напряжений для разных участков сейсмофокальной зоны от поверхности до больших глубин, в том числе отдельно для верхнего и нижнего слоя двойной сеймофокальной зоны на всем протяжении дуги, кроме района о. Итуруп, где двойную структуру выявить не удалось. В работах представлены таблицы параметров главных осей напряжений для крупных кластеров, что удобно для сравнения.

Главной особенностью предыдущих работ по изучению напряженного состояния сейсмоактивной части слэба является их низкая детальность. В основном оцениваются изменения направления главных осей напряжений с глубиной. При этом распределение глубинной сейсмичности и существующие модели сейсмотомографии показывают, что режим погружения плиты может сильно изменяться и по простиранию сейсмофокальной зоны.

Целью представляемой работы является реконструкция направленности осей главных тектонических напряжений в погружающейся Тихоокеанской литосферной плите на участке промежуточных глубин землетрясений южного фланга Курило-Камчатской субдукционной системы отдельно вдоль верхнего и нижнего слоя двойной сейсмофокальной зоны.

Задачи работы:

- выделить из имеющихся каталогов механизмов очагов землетрясений достаточно представительные выборки событий отдельно для двух слоев сейсмофокальной зоны исследуемого района;

- перевести данные каталогов в систему координат, связанную с погружающейся плитой с учетом ее геометрии;

- провести инверсию механизмов очагов землетрясений имеющихся каталогов и получить вдоль каждого слоя наиболее детальную картину направленности осей главных напряжений.

\section{2. ИСХОДНЫЕ ДАННЫЕ И ИХ ПРЕДВАРИТЕЛЬНЫЙ АНАЛИЗ}

Область исследования выбрана на южном фланге Курило-Камчатской субдукционной системы от южной части о. Хоккайдо примерно до прол. Буссоль Курильской гряды (к юго-западу от о. Симушир). Координаты

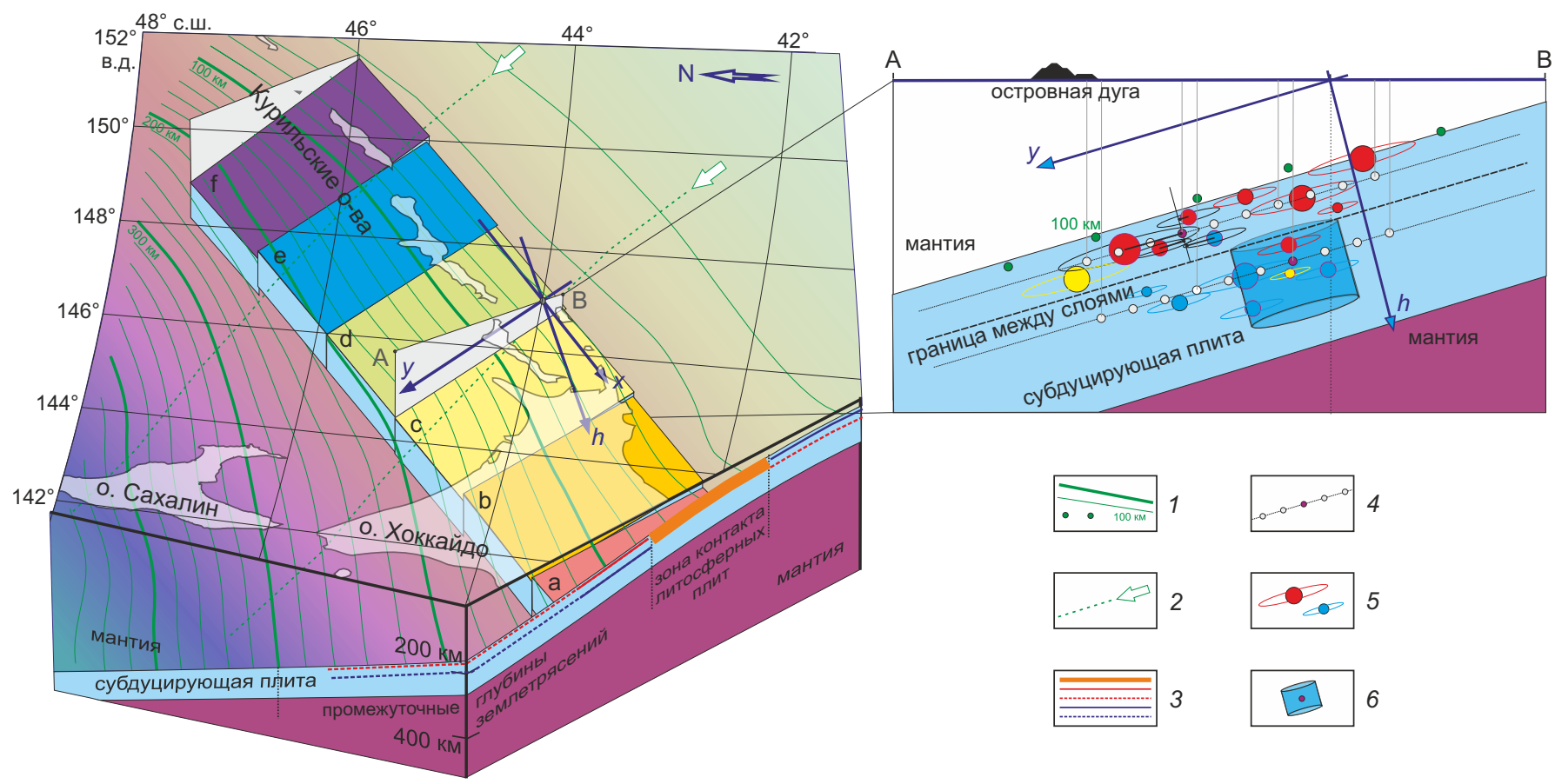

Рис. 1. Схема южного фланга Курило-Камчатской зоны субдукции.

Отмечено положение выделенных сегментов («а» - «f»), осей координатной системы, связанной со слэбом. На врезке А-В справа показано разделение облака гипоцентров землетрясений на слои и формирование неоднородной выборки для отдельного кластера. 1 - изолинии глубины верхней границы сейсмофокальной зоны согласно модели Slab2 [Hayes et al., 2018] на поверхности слэба и вертикальном профиле; 2 - направление погружения Тихоокеанской литосферной плиты; 3 - области активной (сплошные линии) и менее активной (пунктирные линии) сейсмогенерации, красным цветом показаны участки с режимом сжатия вдоль слэба, синим - растяжения, оранжевым - зона контакта плит; 4 - верхняя и нижняя условные 
плоскости и положение расчетных кластеров; 5 - схематические очаги землетрясений и радиус области их упругой разгрузки; 6 - выделение объема среды при формировании выборки землетрясений вторым способом.

Fig. 1. Scheme of the southern flank of the Kuril-Kamchatka subduction zone.

Shown is the position of the selected segments ("a" - "f"), and the axes of the coordinate system associated with the slab. Box A-B on the right shows the division of the earthquake hypocenter cloud into layers and the formation of a heterogeneous sample for a single cluster. 1 - isolines of the depth of the seismic focal zone's upper boundary according to the Slab2 model [Hayes et al., 2018] on the slab surface and vertical profile; 2 - the direction of subduction of the Pacific lithospheric plate; 3 - areas of active (solid lines) and moderately active (dotted lines) seismogeneration, red shows areas with compression regime along the slab, blue - tension, orange - the plate contact zone; 4 - upper and lower reference planes and the position of clusters; 5 - schematic earthquake foci and the radius of their area of elastic discharge; 6 - the selected area for the earthquake sampling by the second method.

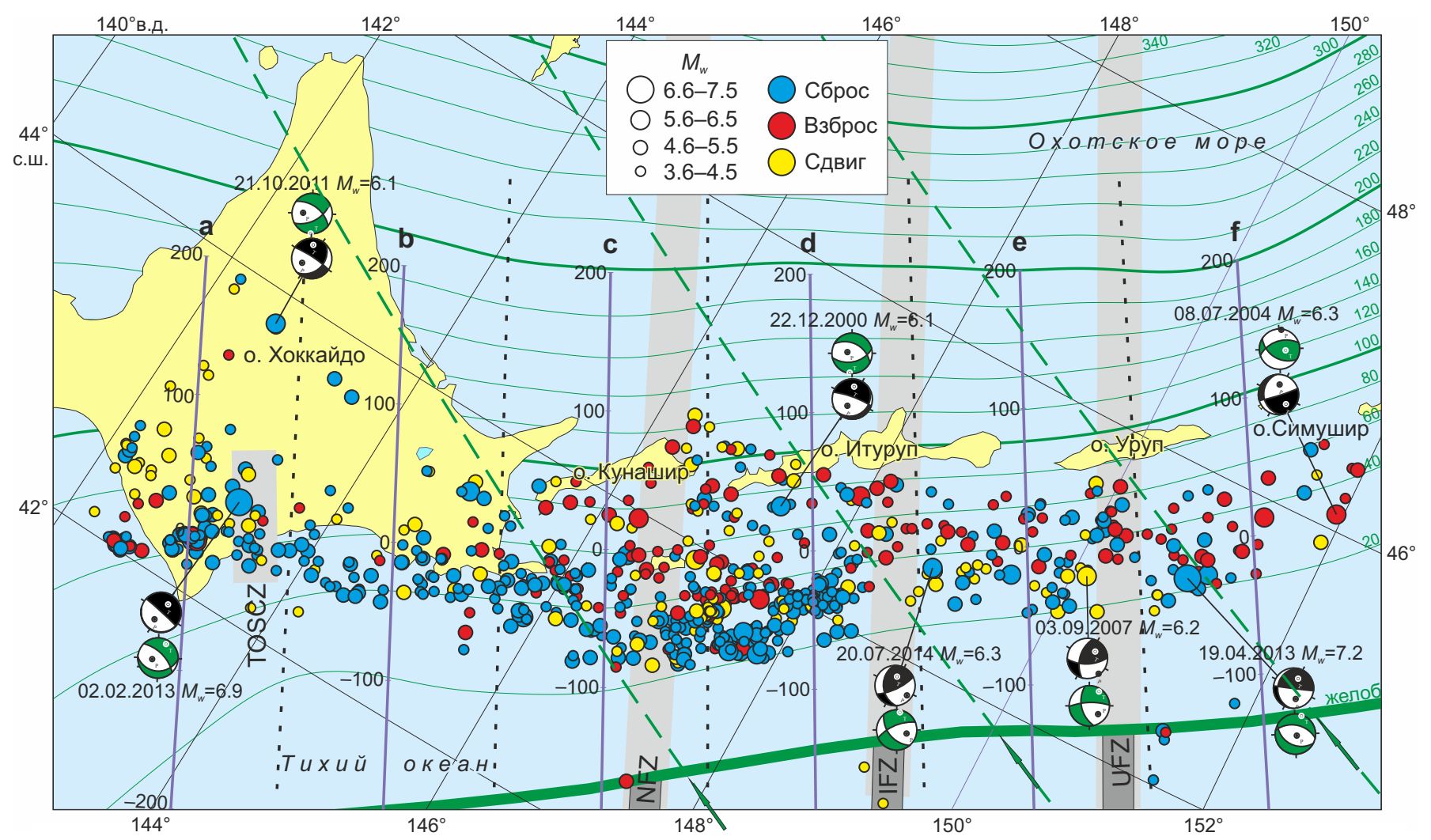

Рис. 2. Землетрясения с известным механизмом очага и глубиной гипоцентра 50-250 км по данным NIED 2000-2019 гг. Цветом показан кинематический тип сейсмодислокации в очаге относительно слэба. Приведены даты и механизм очага наиболее сильных, $M_{w}>6.0$, событий с затемненной областью волн сжатия черным светом - в системе координат, связанной с поверхностью Земли, зеленым цветом - в системе координат, связанной со слэбом. Пунктиром показаны границы секций «a» - «f». Зелеными линиями показаны изолинии глубины верхней границы сейсмофокальной зоны согласно модели Slab2 [Hayes et al., 2018], стрелками и зеленым пунктиром - направление поддвига Тихоокеанской плиты. Серым цветом показано предполагаемое продолжение на слэбе трансформных разломов Носаппу (NFZ), Итуруп (IFZ) и Уpyп (UFZ), a также TokachiOki slab-cracking zone (TOSCZ).

Fig. 2. Earthquakes with known focal mechanisms and hypocenter depths of 50-250 km according to NIED 2000-2019.

The colors show the kinematic type of seismic dislocation relative to the slab. The dates and focal mechanism of the strongest $M_{w}>6.0$ events with a shaded area of compression waves shown: black - in the coordinate system associated with the surface; green - in the coordinate system associated with the slab plane. Dotted lines show the borders of sections "a" - "f". The green lines show the isolines of the upper boundary depth of the seismic zone according to the Slab2 model [Hayes et al., 2018]. The arrows and the green dotted lines indicate the direction of the Pacific Plate subduction. The inferred continuation of the Nosappu (NFS), Iturup (IFS), and Urup (UFS) transform faults, as well as the Tokachi-Oki slab-cracking zone (TOSCZ), is shown in gray.

исследуемого района: $42-49^{\circ}$ с.ш., $142-152^{\circ}$ в.д. (рис. 1 , 2). Согласно модели Slab2 [Hayes et al., 2018] этот участок слэба на южном фланге Курило-Камчатской субдукционной системы относительно ровный (см. рис. 1), а потому удобен для разделения на слои. Юго-западнее выбранного участка находится стык субдукционных систем, а северо-восточнее угол погружения значительно увеличивается. В пределах участка угол наклона слэба также несколько меняется, выполаживаясь к юго-западу примерно с 42 до $29^{\circ}$. Кроме того, изолинии глубины немного выгнуты, азимут их простирания изменяется примерно на $10^{\circ}$. Чтобы учесть это 
изменение наклона, а также для удобства рассмотрения территория разделена поперек островной дуги на шесть сегментов «а» - «f» шириной около 150 км.

Традиционно положение гипоцентров землетрясений и классификацию механизмов по типу напряженного состояния в очаге привязывают к координатной системе, связанной с поверхностью Земли. Используются географические координаты и глубина, направленные на восток, север и вниз, или, к примеру, Гарвардский стандарт USE (вверх, юг, восток), применяемый для тензоров сейсмического момента центроида. В данной работе исследуются напряжения, возникающие в относительно тонком слое, погружающемся в мантию Земли под некоторым углом. Удобно перейти к системе координат, связанной с этим слоем (слэбом). За направления осей новой координатной системы приняты простирание слэба для всех сегментов «а» - «f» (см. рис. 1), равное $240^{\circ}$ от направления на север ( $x$ на рис. 1), и индивидуальное для каждого сегмента направление падения (у на рис. 1), угол которого относительно поверхности изменяется от $29^{\circ}$ («а») до $41^{\circ}$ («f») (табл. 1). Ось х общая для всех сегментов и проходит через точку с географическими координатами $147^{\circ}$ в.д., $44^{\circ}$ с.ш. вдоль поверхности Земли. Третья ось координатной системы перпендикулярна первым двум ( $h$ на рис. 1$)$. Разворот координатной системы положения гипоцентров землетрясений и тензоров сейсмического момента рассмотрен в работе [Safonov, 2019]. Ввиду разного угла наклона осей $y$ и $h$ создается уступ между соседними сегментами. Однако возникающая из-за уступа разница положения землетрясений в координатных системах соседних сегментов невелика (см. рис. 1), можно рассматривать все облако гипоцентров землетрясений как непрерывное.

Гипоцентры землетрясений занимают некоторый объем в верхней части погружающейся в мантию литосферной плиты (см. рис. 1). Основной задачей было разделить этот объем на две области, преимущественно содержащие события, произошедшие в различных сейсмотектонических условиях. Для упрощения задачи было сделано допущение, что граница между слоями параллельна верхней границе сейсмофокальной зоны, плоскости, примерно согласующейся с моделью Slab2 [Hayes et al., 2018], и ортогональной оси $h$. Общая толщина сейсмогенерирующего слоя составляет 40-50 км (рис. 3). Каждая расчетная точка содержит оценку типа напряженного состояния цилиндрического объема пространства заданного радиуса толщиной примерно 20-25 км выше либо ниже уровня плоскости разделения каталога (см. рис. 1 (6)). Чтобы скорректировать это для дальнейших построений, были введены две условные плоскости, параллельные плоскости разделения каталога (см. рис. 1 (5)) и смещенные относительно нее по оси $h$ на 10 км в сторону поверхности Земли (условная плоскость верхнего слоя) и на 10 км от поверхности (условная плоскость нижнего слоя). Параметры условных плоскостей приведены в табл. 1.

Наиболее полную информацию о механизмах очагов землетрясений изучаемого района в последние два десятилетия получает Национальный исследовательский институт наук о Земле и противодействии стихийным бедствиям Японии [NIED F-net..., 2020]. Достоинством каталога NIED является его полнота - обрабатываются события с моментной магнитуды $M_{w}=3.5$ на территории Японии и в непосредственных окрестностях. Недостаток - доступны данные с 1997 г. При расчете тензора сейсмического момента используется эпицентр Японского метеорологического агентства (JMA), глубина центроида уточняется с дискретностью в 3 км, достаточной для целей данной работы. На рис. 2 и 3 показаны землетрясения каталога NIED с 2000 по 2019 г. с магнитудой $M_{\text {jma }} \geq 4.0$ и глубиной центроида 50-250 км в исследуемом районе. Цветом отмечен тип сейсмодислокации в очаге в классификации относительно слэба (красные - взбросы, синие - сбросы, желтые - сдвиги).

Отдельно на рис. 2, 3 показаны механизмы очагов (тензоры сейсмического момента в приближении

Таблица 1. Параметры условных плоскостей и используемые данные

Table 1. The parameters of the reference planes and the data used

\begin{tabular}{|c|c|c|c|c|c|c|c|}
\hline Сегмент & $\mathrm{a}$ & $\mathrm{b}$ & $c$ & $\mathrm{~d}$ & $\mathrm{e}$ & $\mathrm{f}$ & \\
\hline \multicolumn{8}{|c|}{ Параметры верхней и нижней условных плоскостей } \\
\hline Угол простирания, 우 & 240 & 240 & 240 & 240 & 240 & 240 & \\
\hline Угол падения, 우 & 29 & 36 & 37 & 37 & 40 & 42 & \\
\hline $\begin{array}{l}\text { Глубина плоскостей } \\
\text { вдоль оси } h, \text { км (NIED) }\end{array}$ & $\begin{array}{l}55 \\
75\end{array}$ & $\begin{array}{l}60 \\
80\end{array}$ & $\begin{array}{l}71 \\
91\end{array}$ & $\begin{array}{l}71 \\
91\end{array}$ & - & - & \\
\hline \multicolumn{7}{|c|}{ Количество механизмов очагов землетрясений } & Всего \\
\hline NIED верхний слой & 123 & 51 & 101 & 173 & - & - & 448 \\
\hline NIED нижний слой & 33 & 31 & 87 & 81 & - & - & 232 \\
\hline GCMT верхний слой & - & - & 32 & 30 & 9 & 24 & 95 \\
\hline GCMT нижний слой & - & - & 46 & 49 & 25 & 22 & 142 \\
\hline
\end{tabular}



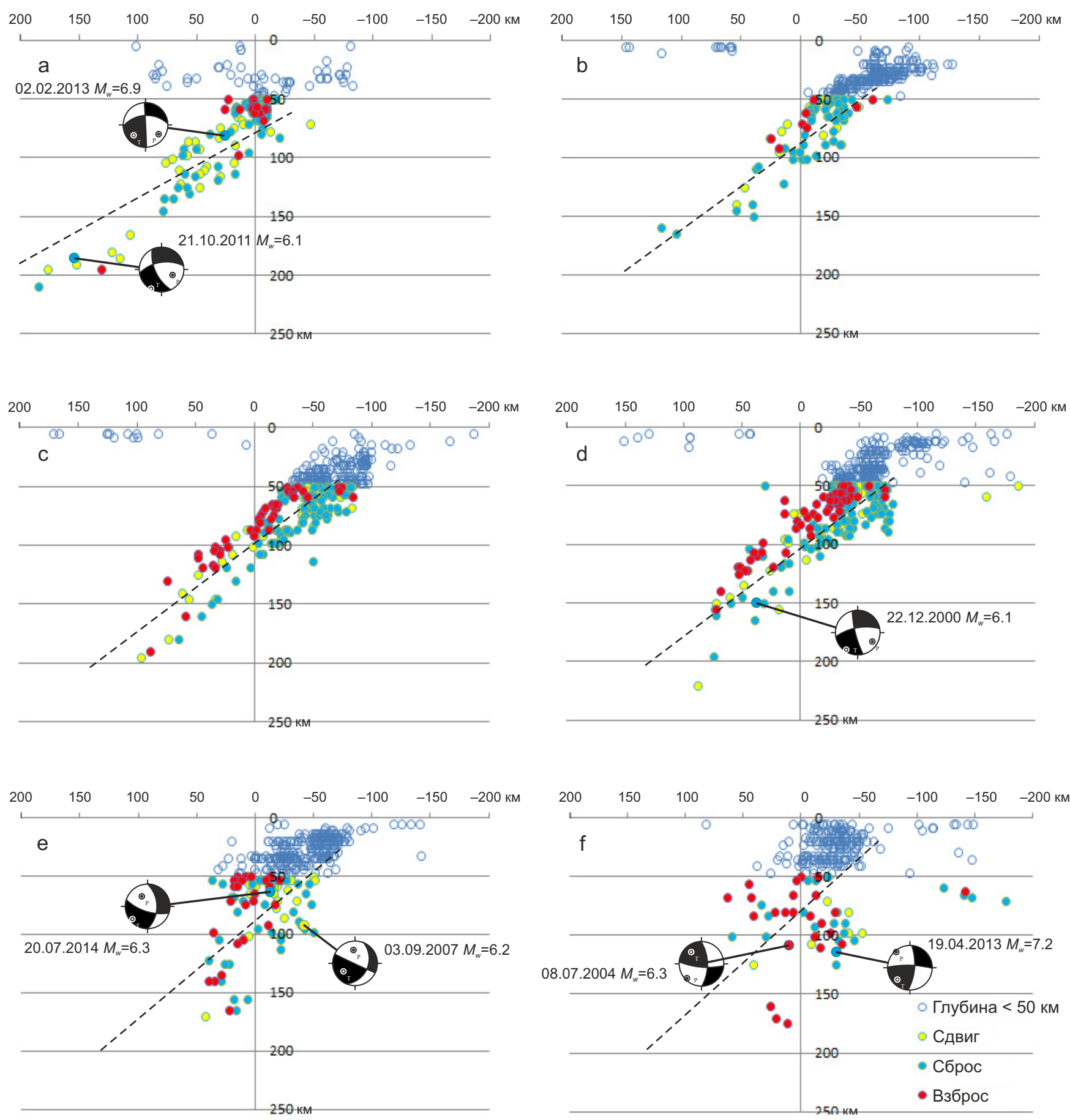

Рис. 3. Землетрясения с известным механизмом очага по данным NIED 2000-2019 гг. в вертикальной проекции по сегментам (см. рис. 2).

Цветом показан кинематический тип сейсмодислокации в очаге относительно слэба, пунктиром - наклон слэба на этом участке, согласующийся с моделью Slab2 [Hayes et al., 2018], помещенный на границу двух слоев. Показаны механизмы очагов сильнейших событий $\left(M_{w}>6.0\right)$ в проекции на вертикальный срез.

Fig. 3. Earthquakes with known focal mechanisms according to NIED 2000-2019 in vertical projection by segments (see Fig. 2). The colors show the kinematic type of seismic dislocation relative to the slab, and the dotted line shows the approximate angle of the slab in this area, consistent with the Slab2 model [Hayes et al., 2018] placed on the border of two layers. The focal mechanisms of the strongest events $M_{w}>6.0$ are shown in vertical projection. 
двойного диполя) сильнейших землетрясений, $M_{w}>6.0$, изучаемого участка сейсмофокальной зоны по данным NIED в традиционной координатной системе (черные) и в проекции на условные плоскости (зеленые). Эти сильные события исключены из каталога для уменьшения магнитудного диапазона землетрясений, подготовленных для инверсии, что является требованием методики, однако могут сопоставляться с результатом реконструкции поля напряжений отдельно.

Как видно из рис. 3, возможности сейсмологической сети ЈМА позволяют уверенно локализовать гипоцентры землетрясений только на ограниченном расстоянии от сейсмологической сети Японии. Так, в секциях «a» - «d» достаточно четко, особенно после классификации землетрясений по типу сейсмодислокации, выделяется двухслойная сейсмогенерирующая структура в зоне промежуточных глубин под территорией Хоккайдо и самого юга Курильской гряды. Можно отметить асейсмичный промежуток в сегментах «а» и «с», менее уверенно - в сегментах «b» и «d».

В секциях «е» - «f» из-за слабого азимутального охвата территории сейсмологической сетью, расположенной на о. Хоккайдо, на вертикальных секциях уже не видно не только двухслойной, но даже однослойной сейсмофокальной зоны. Использовать такие данные для инверсии механизмов очагов послойно невозможно.
Дополнительно были привлечены данные Global CMT project [Global CMT Catalog, 2020] (рис. 4). Как и в случае с каталогом NIED, использовалась глубина центроида. Достоинством каталога тензоров сейсмического момента GlobalCMT является более длительный промежуток времени, им охватываемый, и однородность данных вдоль всей зоны субдукции. Недостаток - меньшая полнота, представительным каталог заявлен только с магнитуды $M_{w}>5.0$, что сильно уменьшает объем выборки событий. В отличие от данных NIED, точность гипоцентрии землетрясений GCMT не позволяет увидеть асейсмичный слой при построении вертикальных срезов (рис. 5).

Более длительный интервал каталога позволил отметить наиболее сильные землетрясения изучаемого района с известными механизмами очага (см. рис. 4). Это самое сильное событие 1978 г. с магнитудой $M_{w}=7.8$, произошедшее по данным каталога [Global CMT Cata$\log , 2020]$ на глубине 181 км в сегменте «с» [Kasahara, Sasatani, 1985]; сильное событие 1993 г. под о. Хоккайдо (Kushiro-Oki) с $M_{w}=7.6$, сегмент «b» [Ozel, Moriya, 1999]; Урупское землетрясение 2013 г. с $M_{w}=7.3$, сегмент «f» [Safonov et al., 2015]. Также на рис. 4 показан механизм очага Шикотанского землетрясения 1994 г. с $M_{w}=8.4$, которое относят к межплитовым либо произошедшим внутри аккреционной призмы над плоскостью поддвига Тихоокеанской плиты [Tikhonov, Shevchenko, 2015].

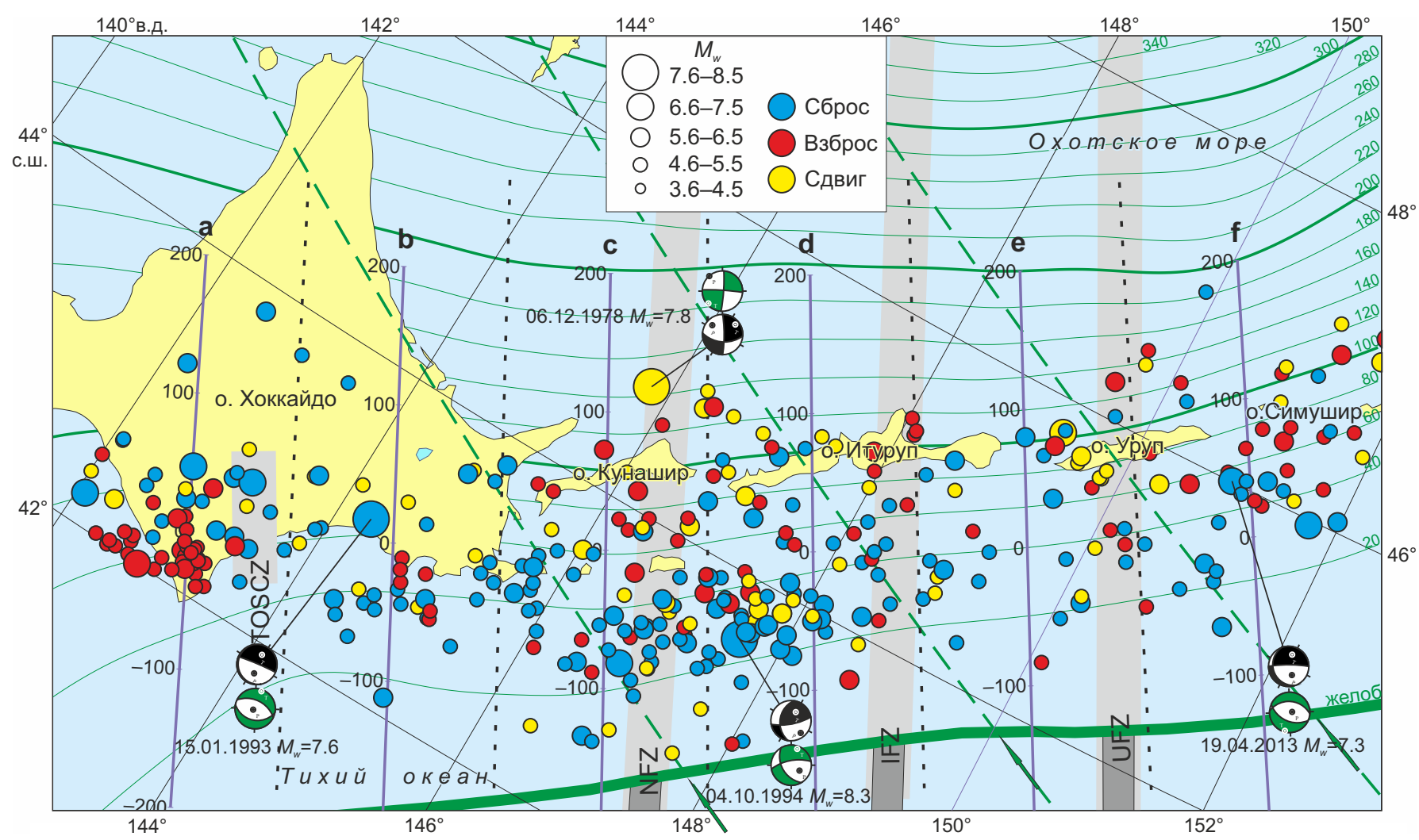

Рис. 4. Землетрясения с известным механизмом очага и глубиной гипоцентра 50-250 км по данным GCMT 1976-2019 гг. Приведены даты и механизм очага наиболее сильных $M_{w}>7.0$ событий. Условные обозначения см. на рис. 2.

Fig. 4. Earthquakes with known focal mechanisms and hypocenter depths of 50-250 km according to GCMT 1976-2019. The dates and focal mechanism of the strongest $M_{w}>7.0$ events. Legend is the same as in Fig. 2. 

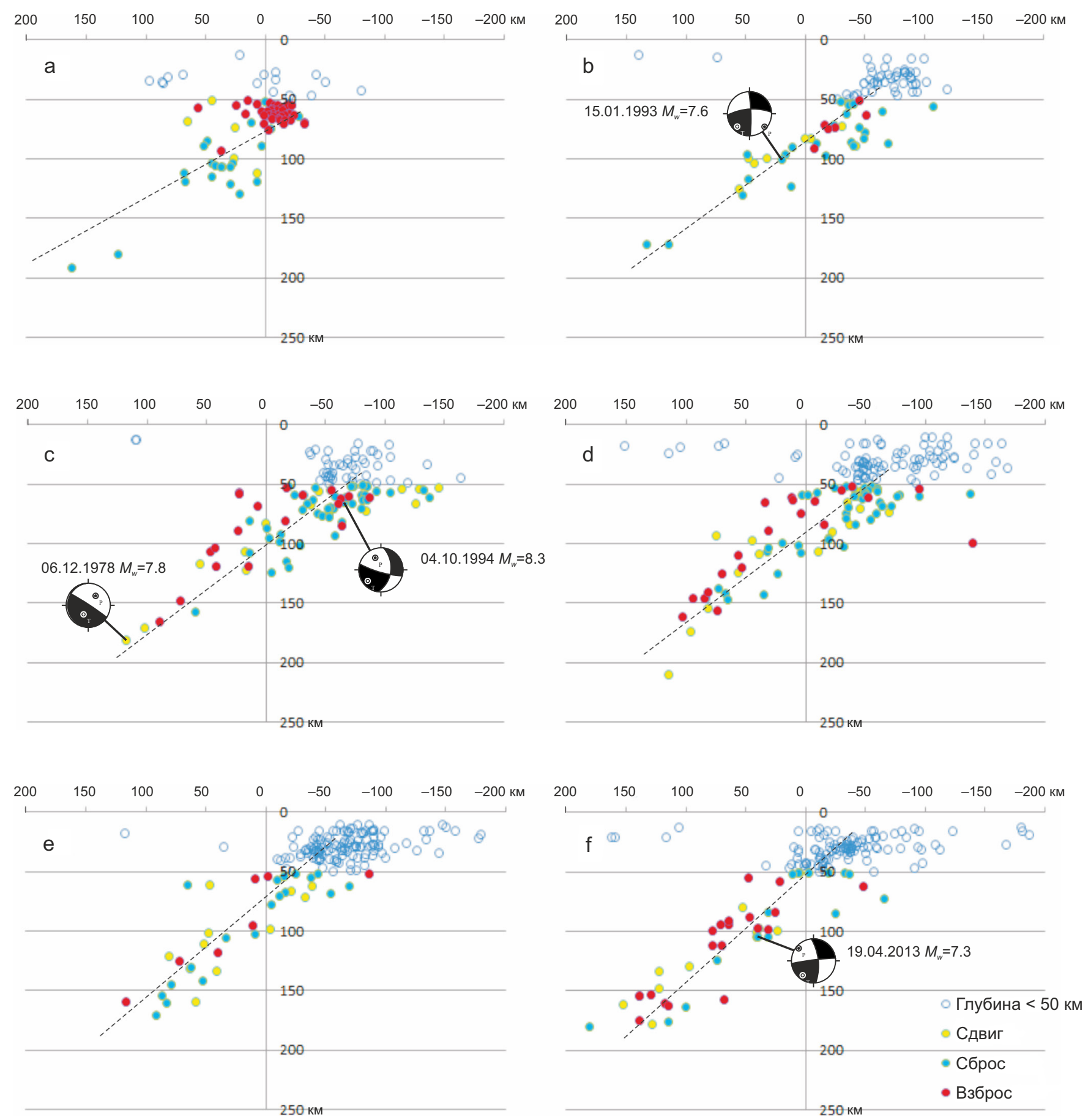

Рис. 5. Землетрясения с известным механизмом очага по данным GCMT 1976-2019 гг. в вертикальной проекции по сегментам (см. рис. 4).

Цветом показан кинематический тип сейсмодислокации в очаге относительно слэба, пунктиром - примерный наклон слэба на этом участке, согласующийся с моделью Slab2 [Hayes et al., 2018], помещенный на границу двух слоев. Показаны механизмы очагов сильнейших событий $M_{w}>7.0$ в проекции на вертикальный срез.

Fig. 5. Earthquakes with known focal mechanisms according to GCMT 1976-2019 in vertical projection by segments (see Fig. 4). The colors show the kinematic type of seismic dislocation relative to the slab, and the dotted line shows the approximate angle of the slab in this area, consistent with the Slab2 model [Hayes et al., 2018] placed on the border of two layers. The focal mechanisms of the strongest events $M_{w}>7.0$ are shown in vertical projection. 
Как видно из рис. 5, координаты гипоцентров землетрясений по данным [Global CMT Catalog, 2020] не позволяют уверенно выделить двуслойную структуру сейсмичности в области промежуточных глубин землетрясений. В связи с этим разделение землетрясений проводилось на основании кинематического типа сейсмодислокации в очаге с учетом угла наклона сейсмофокальной зоны (пунктирная линия на рис. 5) в качестве ориентира. Такой способ, несомненно, менее надежен, хотя тоже применим, например, в работе [Christova, 2015]. В сегментах «a» - «b» на основе этих данных выделить двухслойную структуру не удалось. В сегментах «c», «d», «f» преобладание взбросов в верхней и сбросов в нижней (относительно слэба) части сейсмофокальной зоны позволило установить примерную границу слоев (пунктир на рис. 5, с - d). В сегменте «е» оказалось слишком мало событий взбросового типа в верхней части сейсмофокальной зоны, большинство землетрясений было отнесено к нижнему слою по аналогии с соседними сегментами, хотя такой подход может быть ошибочным. Для инверсии приняты события магнитудного диапазона $M=5.0-7.0$.

Таким образом, получены два каталога для верхнего и два для нижнего слоя сейсмофокальной зоны, частично пересекающиеся в сегментах «с» и «d». Принято решение не совмещать каталоги, так как на общих участках данных достаточно для инверсии, а менее обеспеченные данными крайние участки не пересекаются. К тому же каталоги разнородны по времени и магнитудному диапазону. Принятый подход позволил сравнить результаты, полученные по материалам из альтернативных источников, составить представление об устойчивости полученных решений. Распределение количества данных по сегментам показано в табл. 1. Глубина плоскости разделения каталогов и условных плоскостей вдоль оси $h$ максимальна в центральных сегментах и уменьшается к фланговым. Это является следствием изгиба дуги при неизменном положении общей для всех сегментов оси $x$.

\section{3. ПРИМЕНЯЕМЫЕ МЕТОДЫ}

Для реконструкции поля тектонических напряжений использован метод катакластического анализа (МКА) совокупностей механизмов очагов землетрясений [Rebetsky, 1999, 2003] (I этап). Этот метод позволяет сформировать на основе имеющихся данных однородную выборку механизмов очагов землетрясений, реализовавшихся под влиянием напряженного состояния среды в окрестностях точки расчета. Далее алгоритм МКА на первом этапе реконструкции выполняет определение ориентации главных осей тензора напряжений и значения коэффициента Лоде-Надаи $\mu_{\sigma}$ что характеризует эллипсоид напряжений.

Формирование выборки происходит двумя способами: при первом учитывается положение гипоцентра и размер области упругой разгрузки среды для землетрясений каталога (зависит от магнитуды, см. рис. 1 (5)). Если для кластера не удалось составить выборку событий первым способом, учитываются все гипоцентры внутри цилиндра некоторого радиуса с центральной осью, проходящей через кластер (см. рис. 1 (6)). Каждая составленная неоднородная выборка проходит проверку на выполнение условий однородности упорядоченного распределения необратимых деформаций [Rebetsky, 2007]; это особенно важно при достаточно низкой точности определения положения гипоцентра землетрясения. События, значительно отличающиеся от основной совокупности выборки и не прошедшие проверку на однородность, не учитываются. Методика, реализованная в программе STRESSseism [Rebetsky, 1999, 2003], производит поиск оптимальных параметров напряженного состояния в узлах (кластеpax) двумерной сетки заданного масштаба. С учетом относительно малой толщины сейсмофокальной зоны поворот системы координат позволил использовать особенность данной реализации методики без деления всего объема мантии на произвольные горизонтальные слои, как, например, в работе [Polets, 2018], где также используется МКА. Для условных плоскостей верхнего и нижнего слоя сейсмофокальной зоны шаг сетки составляет 10 км вдоль осей $x$ и $y$, т.е. по простиранию и падению плоскости.

Оптимально, чтобы в исследуемой точке пересекались области упругой разгрузки шести и более землетрясений, прошедших проверку на однородность. При меньшем количестве надежность оценки параметров напряженного состояния среды падает.

Поскольку плотность гипоцентров землетрясений каталога очень неравномерна, расчет проводился в три итерации. Для кластеров, в которых не удалось получить однородную выборку обоими способами, поиск повторялся с уменьшением минимального количества событий в однородной выборке от шести в первой итерации до четырех в третьей и увеличением размеров области осреднения во втором способе выборки (20, 30, 40 км).

Результаты представлены в виде схем напряженного состояния в расчетных кластерах в пределах условных плоскостей сегментов, совмещенных на плоскости рисунка (рис. $6,7,8,9)$. На рисунок спроецированы вертикально относительно поверхности Земли очертания береговых линий, географической координатной сетки. Искажения при проецировании под разным углом сглажены. Показано направление погружения литосферной плиты в мантию в районе глубоководного желоба. Для крупных и относительно однородных участков полей выделены характерные кластеры, для которых построена стереографическая проекция положения осей напряжений на условную плоскость (в виде стереограммы механизма очага с зелеными областями волн сжатия) и на поверхность Земли (с черными областями). Для удобства сопоставления для этих же участков показана ориентация главных осей напряжений по данным [Christova et al., 2006; Christova, 2015] (с синими областями, в проекции на поверхность Земли). Параметры главных осей напряжений 
в выбранных кластерах для удобства использования в традиционной системе координат, связанной с поверхностью Земли, а также коэффициент Лоде-Надаи $\mu_{\sigma}$ представлены в табл. 2, 3, 4, 5.

Для классификации геодинамических типов напряженного состояния среды в зависимости от ориентации главных осей напряжений относительно принятой координатной системы используется подход Ю.Л. Ребецкого и его соавторов (например [Rebetsky, Polets,
2014]), согласно которому есть шесть возможных вариантов:

1) режим горизонтального растяжения;

2) режим горизонтального растяжения со сдвигом;

3) режим горизонтального сдвига;

4) режим горизонтального сжатия со сдвигом;

5) режим горизонтального сжатия;

6) режим сдвига в вертикальной плоскости (вертикальный сдвиг).

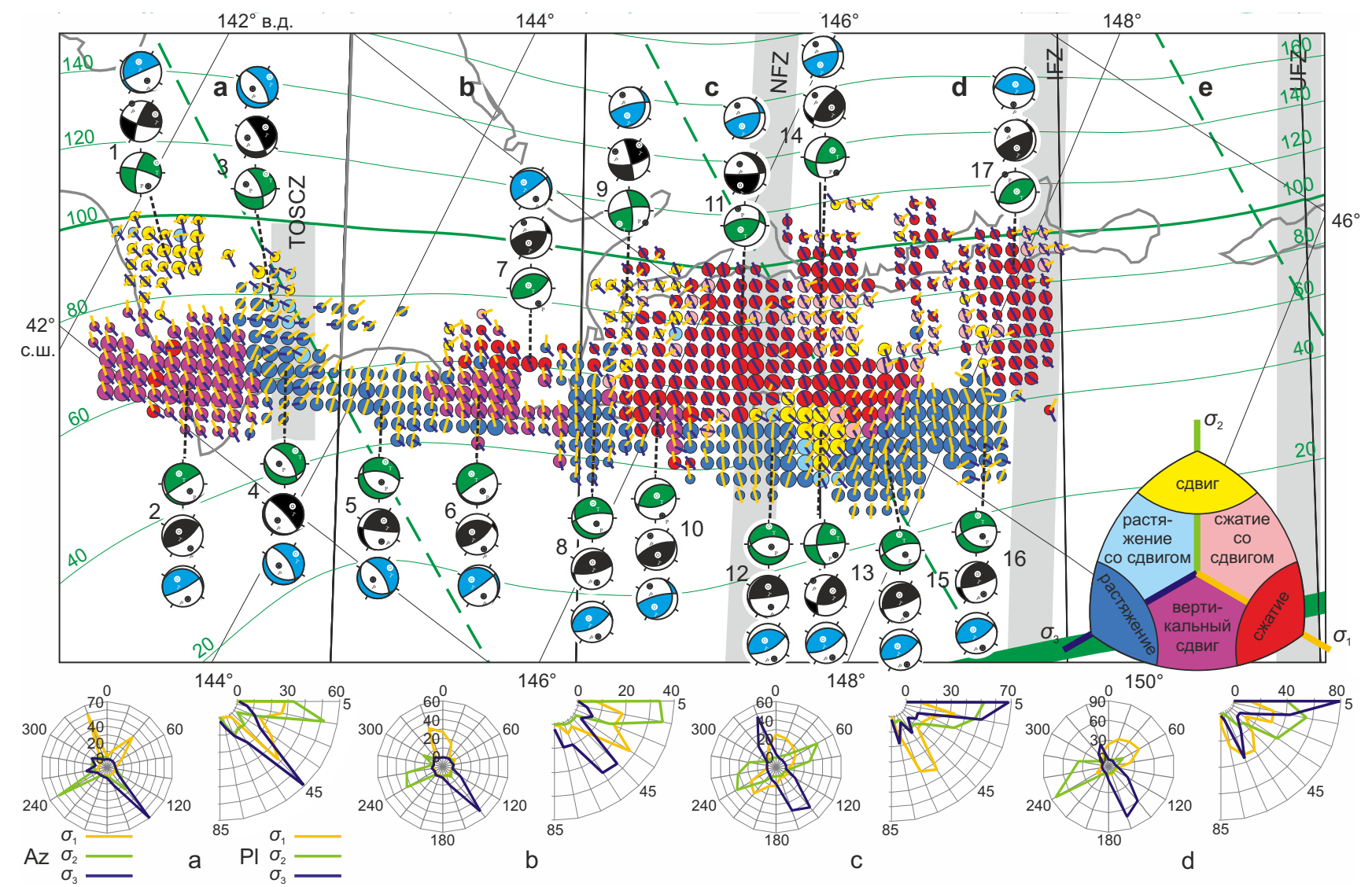

Рис. 6. Поле ориентаций главных тектонических напряжений в южной части Курило-Камчатской зоны субдукции на промежуточных глубинах в верхнем слое на основе данных NIED 2000-2019 гг. в системе координат, связанной с поверхностью слэба.

Окружностями показаны кластеры с реконструированным типом напряженного состояния, цвет соответствует геодинамическому типу напряженного состояние относительно слэба, размер уменьшается с 1 по 3-ю итерацию расчетов. Отрезками на фоне окружностей показаны проекции осей главных напряжений $\sigma_{1}$ (желтые отрезки) и $\sigma_{3}$ (темно-синие отрезки) на условную плоскость, если их угол с плоскостью составляет не более $60^{\circ}$. Оси построены в направлении нижнего полупространства. Длина отрезка пропорциональна косинусу угла погружения, при угле погружения менее $18^{\circ}$ отрезок пересекает окружность. Зелеными линиями показаны изолинии глубины верхней границы сейсмофокальной области согласно модели Slab2 [Науеs et al., 2018], зеленым пунктиром - направление движения Тихоокеанской плиты под глубоководный желоб. Для некоторых кластеров поле напряжений показано в виде механизма очага: зеленые - в проекции на плоскость слэба, черные - в проекции на поверхность Земли, синие - по данным работ [Christova et al., 2006; Christova, 2015]. Серыми полосами отмечено предполагаемое положение разломных зон. Внизу - распределение количества кластеров по углу наклона главных осей напряжений относительно условной плоскости и азимуту относительно ее падения.

Fig. 6. Field of the principal tectonic stresses direction in the southern part of the Kuril-Kamchatka subduction zone at intermediate depths in the upper layer based on NIED 2000-2019 data in the coordinate system associated with the slab surface.

The circles show clusters with the reconstructed type of stress state, the color corresponds to the type of stress state in the slab plane, and the size decreases from 1 to 3 iterations of calculations. The segments against the background of the circles show projections of the axes of the principal stresses $\sigma_{1}$ (yellow segments) and $\sigma_{3}$ (blue segments) on the slab plane, if the angle to the plane is no more than $60^{\circ}$. The axes are plotted in the direction of the lower half-space. The length of the segment is proportional to the cosine of the dip angle. If the dip angle is less than $18^{\circ}$, the segment intersects the circle. The green lines show the isolines of the upper boundary depth of the seismic zone according to the Slab2 model [Hayes et al., 2018]. The green dotted line indicates the direction of movement of the Pacific plate beneath the deep-water trough. For some clusters, the stress field is shown like a focal mechanism: with green - in the projection on the slab plane, black - in the projection on the geoid surface, and blue - according to [Christova et al., 2006; Christova, 2015]. Gray stripes indicate the inferred position of fault zones. Below is the cluster's distribution by the dip angle and the azimuth of the principal stress axes relative to the slab plane. 
Таблица 2. Параметры напряженного состояния южной части Курило-Камчатской зоны субдукции на промежуточных глубинах в верхнем слое на основе данных NIED 2000-2019 гг. в системе координат, связанной с поверхностью Земли

Table 2. The stress state parameters of the southern part of the Kuril-Kamchatka subduction zone at intermediate depths in the upper layer based on NIED 2000-2019 data in the coordinate system associated with the Earth's surface

\begin{tabular}{|c|c|c|c|c|c|c|c|c|c|c|c|}
\hline $\begin{array}{l}\text { № } \\
\text { на рис. } 6\end{array}$ & $\begin{array}{c}\text { Долгота, } \\
\text { о в.д. }\end{array}$ & $\begin{array}{l}\text { Широта, } \\
\text { ॰ с.ш. }\end{array}$ & $\begin{array}{c}\text { Глубина*, } \\
\text { км }\end{array}$ & $\mathrm{Pl}$ & $\mathrm{Az}$ & $\mathrm{Pl}$ & $\mathrm{Az}$ & $\mathrm{Pl}$ & $\mathrm{Az}$ & $\mu_{\sigma}$ & $\begin{array}{c}\text { Тип напряженного } \\
\text { состояния** }\end{array}$ \\
\hline 1 & 142.3 & 42.7 & 98 & 21 & 34 & 69 & 207 & 2 & 303 & 0.1 & сдвиг \\
\hline 2 & 143.0 & 42.2 & 59 & 66 & 289 & 3 & 27 & 23 & 118 & 0.1 & вертикальный сдвиг \\
\hline 3 & 143.2 & 42.8 & 83 & 32 & 13 & 21 & 117 & 50 & 235 & -0.5 & растяжение со сдвигом \\
\hline 4 & 143.5 & 42.5 & 64 & 36 & 19 & 3 & 287 & 54 & 194 & -0.1 & растяжение \\
\hline 5 & 144.3 & 42.6 & 56 & 46 & 1 & 24 & 244 & 35 & 137 & 0.1 & растяжение \\
\hline 6 & 144.9 & 42.9 & 62 & 66 & 265 & 14 & 30 & 19 & 125 & 0.0 & вертикальный сдвиг \\
\hline 7 & 145.1 & 43.2 & 73 & 65 & 176 & 19 & 40 & 16 & 304 & 0.0 & сжатие \\
\hline 8 & 145.7 & 43.1 & 64 & 62 & 336 & 10 & 225 & 26 & 130 & 0.1 & растяжение \\
\hline 9 & 145.6 & 43.6 & 106 & 11 & 5 & 66 & 122 & 21 & 271 & 0.5 & сдвиг \\
\hline 10 & 146.1 & 43.4 & 70 & 66 & 135 & 3 & 37 & 24 & 306 & 0.1 & сжатие \\
\hline 11 & 146.4 & 43.8 & 94 & 33 & 171 & 29 & 61 & 44 & 299 & 0.1 & сжатие \\
\hline 12 & 147.0 & 43.5 & 52 & 49 & 332 & 9 & 232 & 40 & 134 & 0.1 & растяжение \\
\hline 13 & 147.3 & 43.7 & 58 & 53 & 28 & 37 & 195 & 6 & 290 & -0.4 & сдвиг \\
\hline 14 & 146.9 & 44.1 & 100 & 59 & 67 & 19 & 191 & 24 & 290 & 0.3 & сжатие со сдвигом \\
\hline 15 & 147.8 & 43.7 & 46 & 58 & 326 & 10 & 219 & 30 & 123 & 0.2 & растяжение \\
\hline 16 & 148.4 & 44.1 & 52 & 54 & 340 & 21 & 219 & 28 & 118 & 0.6 & растяжение \\
\hline 17 & 148.1 & 44.8 & 118 & 56 & 139 & 12 & 31 & 32 & 294 & 0.1 & сжатие \\
\hline
\end{tabular}

Примечание. ${ }^{*}$ - указана глубина расчетной точки на условной плоскости относительно поверхности Земли. ${ }^{* *}-$ указан тип напряженного состояния кластера относительно условной плоскости.

Note. ${ }^{*}$ - depth of the computational point on the reference plane shown relative to the Earth's surface. ${ }^{* *}$ - stressed-state type of the cluster shown relative to the reference plane.

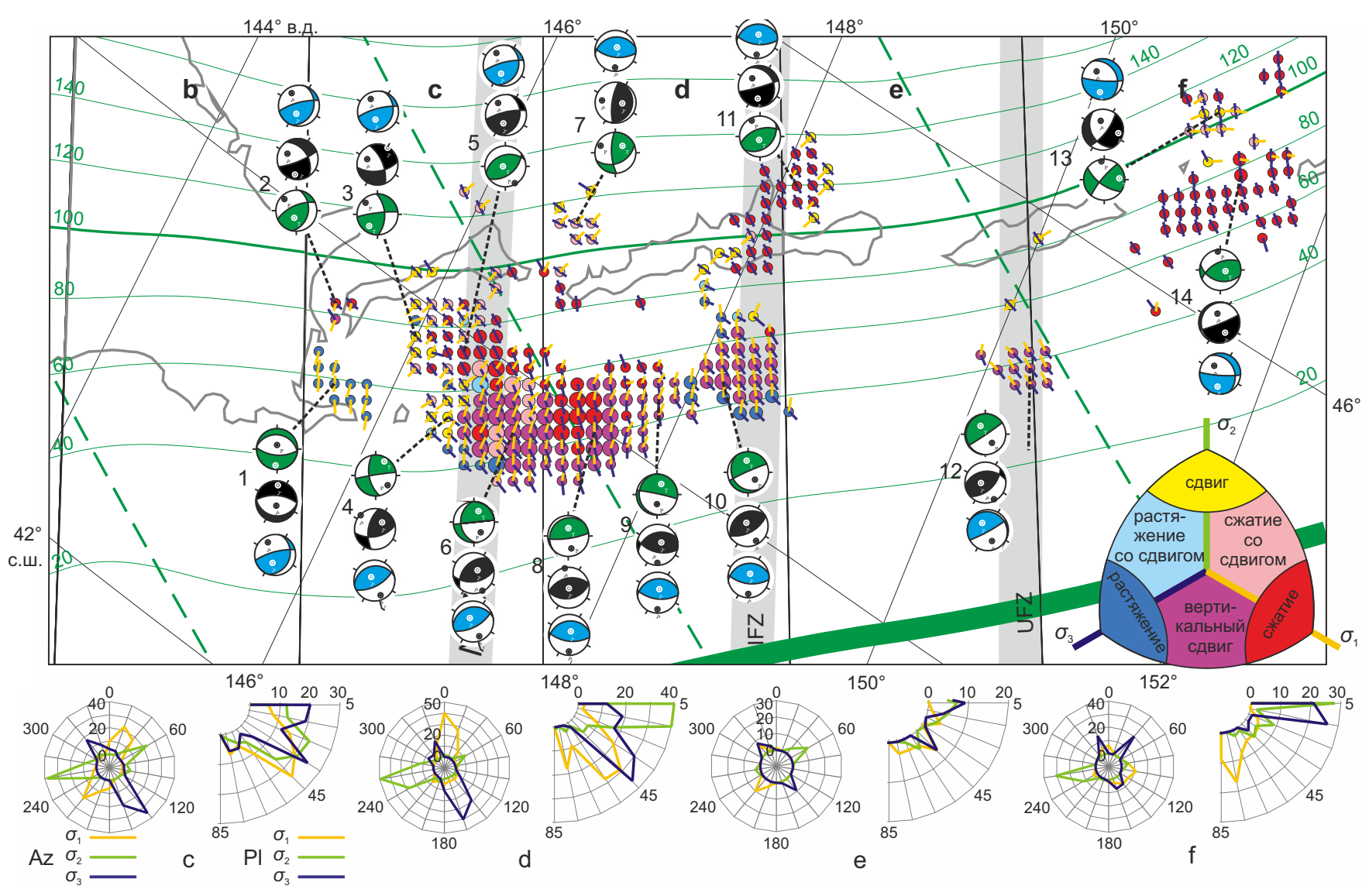

Рис. 7. Поле ориентаций главных тектонических напряжений в южной части Курило-Камчатской зоны субдукции на промежуточных глубинах в верхнем слое на основе данных GCMT 1976-2019 гг. в системе координат, связанной с поверхностью слэба. Условные обозначения см. на рис. 6.

Fig. 7. Field of the principal tectonic stresses direction in the southern part of the Kuril-Kamchatka subduction zone at intermediate depths in the upper layer based on GCMT 1976-2019 data in the coordinate system associated with the slab surface. Legend is the same as in Fig. 6. 
Таблица 3. Параметры напряженного состояния южной части Курило-Камчатской зоны субдукции на промежуточных глубинах в верхнем слое на основе данных GCMT 1976-2019 гг. в системе координат, связанной с поверхностью Земли

Table 3. The stress state parameters of the southern part of the Kuril-Kamchatka subduction zone at intermediate depths in the upper layer based on GCMT 1976-2019 data in the coordinate system associated with the Earth's surface

\begin{tabular}{|c|c|c|c|c|c|c|c|c|c|c|c|}
\hline \multirow{2}{*}{$\begin{array}{l}\text { № } \\
\text { на рис. } 7\end{array}$} & \multirow{2}{*}{$\begin{array}{l}\text { Долгота, } \\
\text { о в.д. }\end{array}$} & \multirow{2}{*}{$\begin{array}{l}\text { Широта, } \\
\text { ॰ с.ш. }\end{array}$} & \multirow{2}{*}{$\begin{array}{l}\text { Глубина*, } \\
\text { км }\end{array}$} & \multicolumn{2}{|c|}{$\sigma_{1}$} & \multicolumn{2}{|c|}{$\sigma_{2}$} & \multicolumn{2}{|c|}{$\sigma_{3}$} & \multirow[t]{2}{*}{$\mu_{\sigma}$} & \multirow{2}{*}{$\begin{array}{c}\text { Тип напряженного } \\
\text { состояния** }\end{array}$} \\
\hline & & & & $\mathrm{Pl}$ & $\mathrm{Az}$ & $\mathrm{Pl}$ & $\mathrm{Az}$ & $\mathrm{Pl}$ & $\mathrm{Az}$ & & \\
\hline 1 & 145.7 & 43.3 & 75 & 19 & 336 & 2 & 245 & 71 & 151 & -0.1 & растяжение \\
\hline 2 & 145.5 & 43.6 & 105 & 21 & 160 & 43 & 48 & 39 & 268 & 0.6 & сжатие \\
\hline 3 & 146.1 & 43.7 & 93 & 4 & 1 & 51 & 96 & 39 & 268 & -0.1 & сдвиг \\
\hline 4 & 146.6 & 43.5 & 63 & 47 & 17 & 43 & 191 & 3 & 284 & 0.2 & сдвиг \\
\hline 5 & 146.5 & 43.8 & 87 & 52 & 167 & 25 & 41 & 27 & 297 & 0.2 & сжатие \\
\hline 6 & 147.0 & 43.6 & 57 & 68 & 24 & 21 & 215 & 4 & 123 & -0.2 & вертикальный сдвиг \\
\hline 7 & 146.8 & 44.6 & 127 & 60 & 66 & 1 & 158 & 30 & 249 & 0.0 & сжатие со сдвигом \\
\hline 8 & 147.6 & 43.9 & 49 & 87 & 140 & 0 & 48 & 3 & 318 & 0.3 & вертикальный сдвиг \\
\hline 9 & 147.9 & 44.2 & 61 & 70 & 28 & 16 & 244 & 11 & 150 & -0.4 & вертикальный сдвиг \\
\hline 10 & 148.3 & 44.4 & 67 & 74 & 309 & 2 & 211 & 15 & 120 & 0.3 & вертикальный сдвиг \\
\hline 11 & 148.2 & 45.4 & 132 & 35 & 155 & 24 & 46 & 45 & 290 & 0.2 & сжатие \\
\hline 12 & 150.4 & 45.3 & 55 & 70 & 235 & 18 & 30 & 8 & 123 & 0.0 & вертикальный сдвиг \\
\hline 13 & 151.0 & 46.8 & 144 & 20 & 73 & 33 & 176 & 50 & 316 & 0.9 & сдвиг \\
\hline 14 & 151.3 & 46.6 & 117 & 39 & 120 & 9 & 217 & 50 & 318 & 0.2 & сжатие \\
\hline
\end{tabular}

Примечание. * - указана глубина расчетной точки на условной плоскости относительно поверхности Земли. ${ }^{* *}-$ указан тип напряженного состояния кластера относительно условной плоскости.

Note. * - depth of the computational point on the reference plane shown relative to the Earth's surface. ${ }^{* *}-$ stressed-state type of the cluster shown relative to the reference plane.

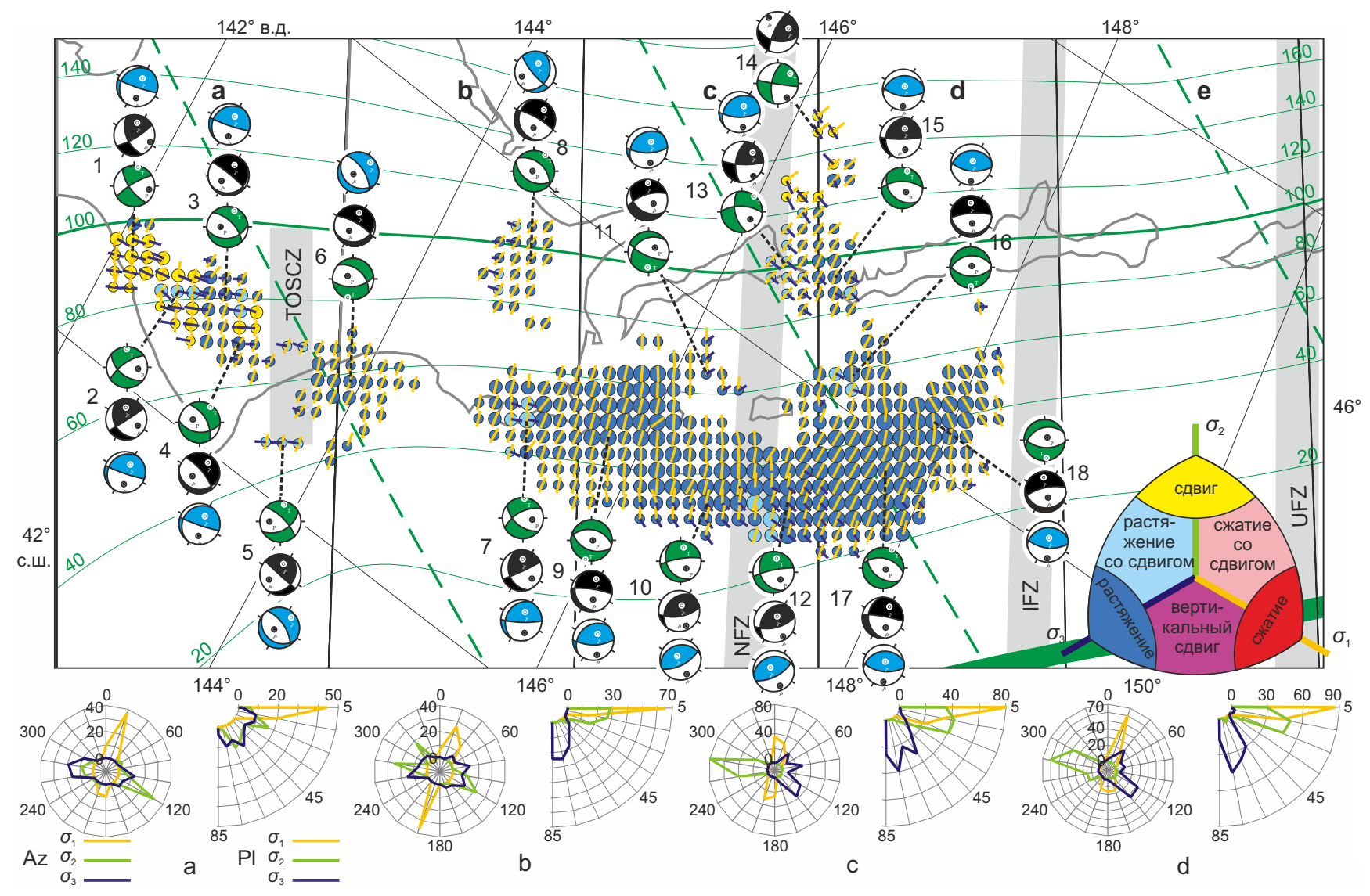

Рис. 8. Поле ориентаций главных тектонических напряжений в южной части Курило-Камчатской зоны субдукции на промежуточных глубинах в нижнем слое на основе данных NIED 2000-2019 гг. в системе координат, связанной с поверхностью слэба. Условные обозначения см. на рис. 6.

Fig. 8. Field of the principal tectonic stresses direction in the southern part of the Kuril-Kamchatka subduction zone at intermediate depths in the lower layer based on NIED 2000-2019 data in the coordinate system associated with the slab surface. Legend is the same as in Fig. 6. 
Таблица 4. Параметры напряженного состояния южной части Курило-Камчатской зоны субдукции на промежуточных глубинах в нижнем слое на основе данных NIED 2000-2019 гг. в системе координат, связанной с поверхностью Земли

Table 4. The stress state parameters of the southern part of the Kuril-Kamchatka subduction zone at intermediate depths in the lower layer based on NIED 2000-2019 data in the coordinate system associated with the Earth's surface

\begin{tabular}{|c|c|c|c|c|c|c|c|c|c|c|c|}
\hline $\begin{array}{l}\text { № } \\
\text { на рис. } 8\end{array}$ & $\begin{array}{c}\text { Долгота, } \\
\text { в.д. }\end{array}$ & $\begin{array}{l}\text { Широта, } \\
{ }^{\circ} \text { с.ш. }\end{array}$ & $\begin{array}{c}\text { Глубина*, } \\
\text { км }\end{array}$ & $\mathrm{Pl}$ & $\mathrm{Az}$ & $\mathrm{Pl}$ & $\mathrm{Az}$ & $\mathrm{Pl}$ & $\mathrm{Az}$ & $\mu_{\sigma}$ & $\begin{array}{c}\text { Тип напряженного } \\
\text { состояния** }\end{array}$ \\
\hline 1 & 142.2 & 42.6 & 120 & 33 & 343 & 53 & 192 & 15 & 82 & -0.3 & сдвиг \\
\hline 2 & 142.6 & 42.6 & 110 & 38 & 329 & 35 & 205 & 32 & 88 & -0.5 & растяжение со сдвигом \\
\hline 3 & 142.9 & 42.7 & 110 & 38 & 360 & 10 & 98 & 50 & 201 & 0.1 & растяжение \\
\hline 4 & 143.1 & 42.5 & 96 & 29 & 10 & 12 & 107 & 58 & 216 & -0.3 & растяжение \\
\hline 5 & 143.7 & 42.2 & 67 & 41 & 346 & 29 & 104 & 36 & 217 & -0.1 & растяжение со сдвигом \\
\hline 6 & 144.0 & 42.6 & 90 & 29 & 348 & 14 & 86 & 58 & 198 & 0.1 & растяжение \\
\hline 7 & 145.3 & 43.0 & 78 & 40 & 336 & 33 & 213 & 32 & 98 & -0.2 & растяжение со сдвигом \\
\hline 9 & 145.9 & 43.1 & 80 & 33 & 351 & 15 & 251 & 52 & 140 & 0.0 & растяжение \\
\hline 10 & 146.7 & 43.1 & 56 & 63 & 355 & 19 & 221 & 18 & 125 & 0.2 & растяжение \\
\hline 11 & 146.3 & 43.6 & 104 & 15 & 333 & 28 & 235 & 58 & 89 & 0.0 & растяжение \\
\hline 12 & 147.3 & 43.3 & 56 & 64 & 355 & 21 & 216 & 16 & 120 & 0.0 & растяжение \\
\hline 13 & 146.5 & 44.2 & 146 & 31 & 16 & 56 & 223 & 13 & 114 & 0.0 & растяжение со сдвигом \\
\hline 14 & 146.3 & 44.8 & 194 & 40 & 41 & 47 & 191 & 15 & 298 & -0.5 & сдвиг \\
\hline 15 & 146.9 & 44.3 & 140 & 48 & 355 & 24 & 236 & 33 & 130 & 0.1 & растяжение \\
\hline 16 & 147.3 & 44.0 & 104 & 31 & 329 & 4 & 236 & 58 & 140 & -0.2 & растяжение \\
\hline 18 & 148.0 & 44.0 & 86 & 26 & 324 & 8 & 230 & 63 & 124 & 0.4 & растяжение \\
\hline
\end{tabular}

Примечание. ${ }^{*}$ - указана глубина расчетной точки на условной плоскости относительно поверхности Земли. ${ }^{*}$ - указан тип напряженного состояния кластера относительно условной плоскости.

Note. ${ }^{*}$ - depth of the computational point on the reference plane shown relative to the Earth's surface. ** - stressed-state type of the cluster shown relative to the reference plane.

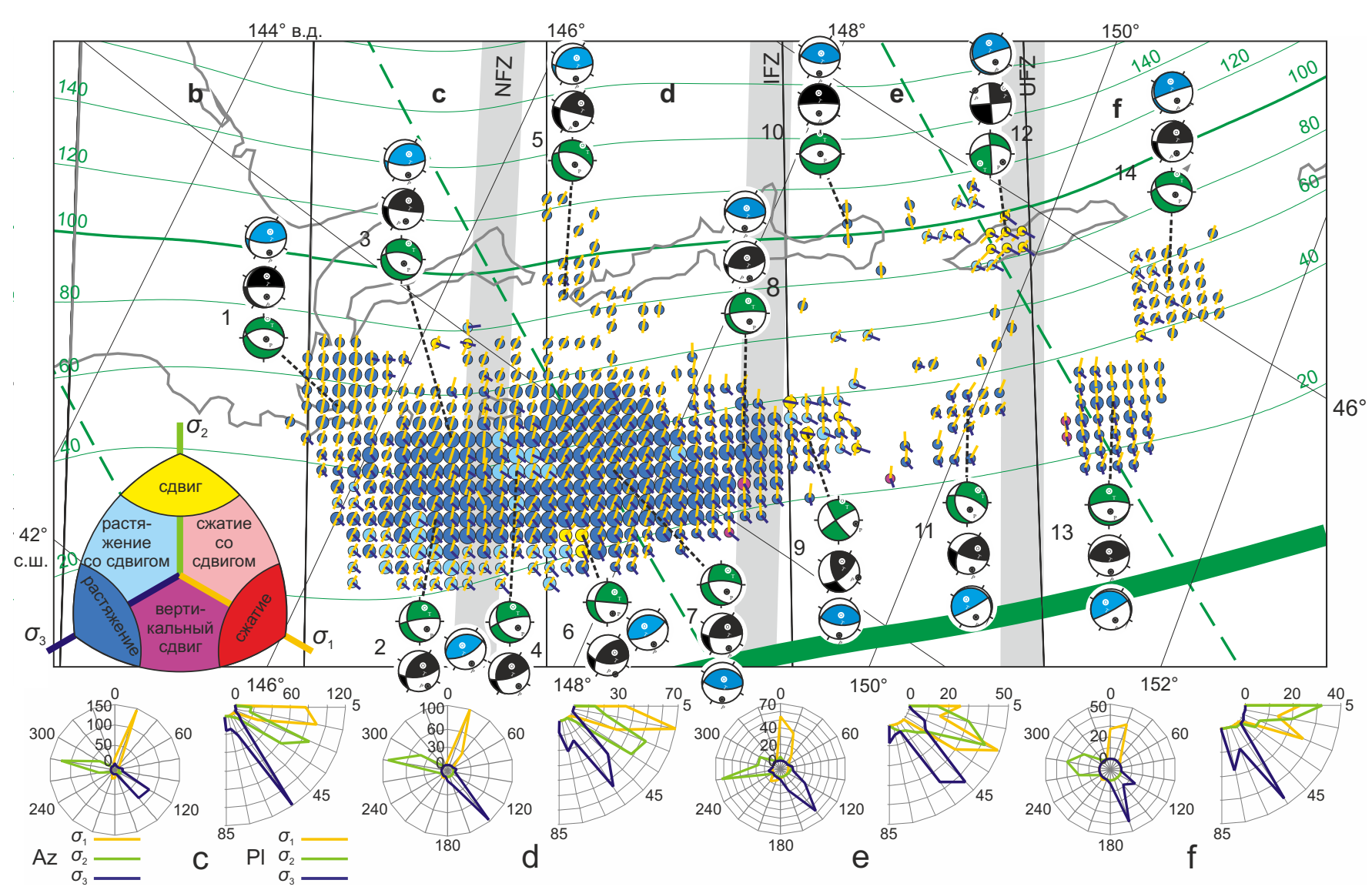

Рис. 9. Поле ориентаций главных тектонических напряжений в южной части Курило-Камчатской зоны субдукции на промежуточных глубинах в нижнем слое на основе данных GCMT 1976-2019 гг. в системе координат, связанной с поверхностью слэба. Условные обозначения см. на рис. 6.

Fig. 9. Field of the principal tectonic stresses direction in the southern part of the Kuril-Kamchatka subduction zone at intermediate depths in the lower layer based on GCMT 1976-2019 data in the coordinate system associated with the slab surface. Legend is the same as in Fig. 6. 
Таблица 5. Параметры напряженного состояния южной части Курило-Камчатской зоны субдукции на промежуточных глубинах в нижнем слое на основе данных GCMT 1976-2019 гг. в системе координат, связанной с поверхностью Земли

Table 5. The stress state parameters of the southern part of the Kuril-Kamchatka subduction zone at intermediate depths in the lower layer based on GCMT 1976-2019 data in the coordinate system associated with the Earth's surface

\begin{tabular}{|c|c|c|c|c|c|c|c|c|c|c|c|}
\hline $\begin{array}{l}\text { № } \\
\text { на рис. } 9\end{array}$ & $\begin{array}{c}\text { Долгота, } \\
\text { о в.д. }\end{array}$ & $\begin{array}{l}\text { Широта, } \\
\text { ॰ с.ш. }\end{array}$ & $\begin{array}{c}\text { Глубина*, } \\
\text { км }\end{array}$ & $\mathrm{Pl}$ & $\mathrm{Az}$ & $\mathrm{Pl}$ & $\mathrm{Az}$ & $\mathrm{Pl}$ & $\mathrm{Az}$ & $\mu_{\sigma}$ & $\begin{array}{c}\text { Тип напряженного } \\
\text { состояния** }\end{array}$ \\
\hline 1 & 145.8 & 43.2 & 91 & 40 & 345 & 16 & 241 & 46 & 134 & -0.1 & растяжение \\
\hline 2 & 146.8 & 43.0 & 49 & 59 & 6 & 27 & 216 & 13 & 119 & 0.1 & растяжение \\
\hline 3 & 146.6 & 43.4 & 79 & 44 & 4 & 26 & 246 & 34 & 137 & 0.4 & растяжение \\
\hline 4 & 147.2 & 43.4 & 67 & 57 & 350 & 26 & 213 & 20 & 113 & -0.2 & растяжение со сдвигом \\
\hline 5 & 146.9 & 44.3 & 125 & 38 & 15 & 34 & 253 & 34 & 137 & -0.1 & растяжение \\
\hline 6 & 147.8 & 43.4 & 35 & 59 & 38 & 31 & 219 & 0 & 129 & 0.0 & сдвиг \\
\hline 7 & 147.8 & 43.8 & 59 & 51 & 10 & 33 & 227 & 19 & 125 & 0.1 & растяжение \\
\hline 8 & 148.6 & 44.2 & 65 & 68 & 2 & 16 & 226 & 14 & 132 & 0.2 & растяжение \\
\hline 9 & 149.0 & 44.5 & 58 & 43 & 345 & 47 & 169 & 2 & 77 & -0.3 & сдвиг \\
\hline 10 & 148.6 & 45.4 & 141 & 40 & 329 & 1 & 59 & 50 & 150 & 0.0 & растяжение \\
\hline 11 & 150.0 & 45.0 & 64 & 43 & 30 & 42 & 244 & 18 & 137 & 0.1 & растяжение \\
\hline 12 & 149.8 & 45.7 & 135 & 1 & 10 & 89 & 162 & 0 & 280 & 0.0 & сдвиг \\
\hline 13 & 151.0 & 45.4 & 52 & 72 & 332 & 3 & 234 & 18 & 143 & 0.1 & растяжение \\
\hline 14 & 151.1 & 46.0 & 99 & 47 & 355 & 24 & 237 & 34 & 130 & 0.0 & растяжение \\
\hline
\end{tabular}

Примечание. * - указана глубина расчетной точки на условной плоскости относительно поверхности Земли. ${ }^{* *}-$ указан тип напряженного состояния кластера относительно условной плоскости.

Note. ${ }^{*}$ - depth of the computational point on the reference plane shown relative to the Earth's surface. ${ }^{* *}$ - stressed-state type of the cluster shown relative to the reference plane.

\section{4. РЕЗУЛЬТАТЫ И ОБСУЖДЕНИЕ}

Удалось получить детальную картину поля ориентаций главных напряжений в пределах изучаемого района сейсмофокальной зоны в обоих слоях, однако на многих участках по менее надежным данным в третьей итерации расчетов. Наиболее надежные данные по обоим вариантам каталога получены в секциях «с» и «d» на глубинах до 100-110 км. При этом в результатах на основе каталогов разных агентств в большей части общих кластеров направления главных осей поля напряжений идентичны или не слишком отличаются, общие закономерности сохраняются. Наименее полная и надежная картина в верхнем слое сегментов «е» и «f».

Все оценки ориентации главных осей напряжений, приведенные на рис. 6, 7, 8, 9, следует воспринимать как относящиеся к глубине в 50 км и более, даже если указана меньшая глубина расчетной точки в табл. 2 , $3,4,5,6,7$.

Полученный результат в целом согласуется с гипотезами образования двухслойной сейсмофокальной зоны на промежуточных глубинах: выявлено преобладание напряжений сжатия вдоль слэба в верхнем слое и растягивающих - в нижнем. При этом на многих участках, особенно в верхнем сейсмогенерирующем слое под территорией Хоккайдо, эта закономерность нарушается. В соответствующих реконструированному полю напряжений механизмах очагов часто присутствует сдвиговая компонента, правосторонняя вдоль более вертикальной плоскости относительно поверхности Земли, что отражает движение слэба под углом к направлению его падения (например, на рис. 8 это стереограммы черного цвета № $7-13,15,17)$.
Вдоль обращенного к желобу края изучаемого участка субдукционной системы (см. рис. 6, 7, 8; рис. 9) располагается кайма из кластеров, в которых преобладает направление девиаторного растяжения вдоль падения слэба под углом в $15-25^{\circ}$ к условной плоскости. Таким образом на плоскость слэба проецируются напряжения зоны контакта литосферных плит, которые при рассмотрении относительно поверхности Земли классифицируются как поддвиг в условиях сжатия $(12,15,16$ на рис. $6 ; 10$ на рис. $7 ; 7,10,12$ на рис. $8 ; 2$, $4,7,11,13$ на рис. 9). Вероятно, зона контакта плит на многих участках попадает в пределы рассматриваемого диапазона глубин, ограниченного в данной работе верхней глубиной в 50 км. Также возможно влияние событий с ошибочно определенной глубиной.

В юго-западной части изучаемого района под о. Хоккайдо (сегменты «a», «b») есть два обширных участка с преобладанием напряженного состояния вертикального сдвига, т.е. примерного равенства углов наклона главных осей $\sigma_{3}$ (наибольшего сжатия) и $\sigma_{1}$ (наименьшего сжатия). Так, с учетом меньшего угла погружения слэба проецируются в принятую систему координат те же напряжения зоны контакта плит (2, 6 на рис. 6).

Глубже в нижнем слое в большей части кластеров преобладает параллельное условной плоскости растяжение, ось которого повернута примерно на $20^{\circ}$ по часовой стрелке от направления падения слэба (к северу, если рассматривать с поверхности). Ось $\sigma_{3}$ здесь преимущественно ортогональна слэбу или падает под крутыми углами, создавая небольшую сдвиговую компоненту напряжений $(3,6,8,9,11,15-18$ на рис. 8; 1, 3, 5, 10 , 14 на рис. 9). В этих условиях реализовалось, например, одно из сильнейших землетрясений промежуточной 
глубины последнего времени - событие 19 апреля 2013 г. с $M_{w}=7.3$ (см. рис. 3).

В верхнем слое в большей части кластеров в сегментах «c», «d», а также частично в сегменте «b» преобладает напряженное состояние сжатия $(7,10,11,14$, 17 на рис. 6; 5, 11, 14 на рис. 7). При этом $\sigma_{3}$ параллельна плоскости слэба и направлена в сторону движения плиты (зеленый пунктир на рис. $6,7,8,9$ ), что составляет угол $30-40^{\circ}$ с направлением ее падения (вверх на рис. $6,7,8,9)$. Ранее установлено, что такое направление главной оси максимального сжатия характерно для поля тектонических напряжений южной части Курило-Камчатской сейсмофокальной зоны и на больших глубинах (300-450 км) [Safonov, 2020] и может быть объяснено сопротивлением вещества мантии движению плиты. Если объяснять напряженное состояние сжатия верхнего слоя исключительно гипотезой обратного изгиба, следует ожидать, что ось максимального сжатия будет направлена перпендикулярно оси изгиба, т.е. в сторону падения плиты. Следовательно, в установившейся здесь системе напряжений изгиб может не являться преобладающей причиной. Вероятно, в нижнем слое разворот оси девиаторного растяжения $\sigma_{1}$ по часовой стрелке относительно падения слэба связан с правосторонней сдвиговой компонентой в погружении слэба в мантию.

Под восточной частью Хоккайдо на границе сегментов «а» и «b» в кластерах верхнего слоя преобладает растяжение вдоль слэба с осью $\sigma_{1}$, повернутой примерно на $20^{\circ}$ по часовой стрелке от падения слэба $(3,4,5$ на рис. 6), т.е. так же, как в нижнем слое (4, 5, 6 на рис. 8). Примерно в этом районе должен находиться субвертикальный разлом плиты (Tokachi-Oki slab-cracking zone) согласно [Katsumata et al., 2003]. Однако в реконструированной системе напряжений наличие вертикального взреза сквозь оба слоя (сдвиговое либо вертикально-сдвиговое напряженное состояние) никак не отразилось, даже если учесть небольшой наклон предполагаемой разломной зоны к северо-востоку. Механизм очага сильного землетрясения 2 февраля 2013 г. (см. рис. 2), предположительно произошедшего в верхнем слое, соответствует реконструированному полю напряжений (верхнему и нижнему).

Близко к реконструированному полю напряжений находятся и условия, в которых реализовалось сильнейшее под территорией Хоккайдо на промежуточных глубинах землетрясение 15 января 1993 г. (Kushiro-Oki) с $M_{w}=7.6$ [Ozel, Moriya, 1999]. Хотя непосредственно в гипоцентре этого события получить оценку не удалось, соответствующее его механизму поле напряжений наблюдается в кластерах нижнего слоя под северо-восточной частью Хоккайдо (8 на рис. 8). Необходимо напомнить, что это и другие сильные события не участвовали в реконструкции поля напряжений, а использованный для реконструкции каталог начинается в 2000 г.

Напряженное состояние сдвига наблюдается в сегменте «а» на глубинах больше 70 км в верхнем (1, 3 на рис. 6$)$ и нижнем слое $(1,2$, на рис. 8), азимут главных осей напряжений в верхнем и нижнем слое отличается на $20^{\circ}$.

Примерно в 10 \% кластеров верхнего и 12 \% нижнего слоя преобладает геодинамический тип напряженного состояния сдвига (желтый цвет). Серыми полосами на рис. 6, 7, 8, 9 показано продолжение на плоскость слэба трансформных разломов, выявленных на Тихоокеанской плите. В некоторых случаях кластеры желтого цвета попадают на продолжение разломных зон, как, например, 4 на рис. 7, 12 на рис. 9. В большинстве случаев группы кластеров со сдвиговым типом напряженного состояния с продолжением зон трансформных разломов не совпадают. В пользу связи разломов Носаппу, Итуруп, Уруп с происходящими внутри погруженной плиты сдвиговыми землетрясениями говорит направление главных осей напряжений в большинстве желтых кластеров - в таких условиях реализуются левосторонние сдвиги по падению слэба $(1,9,13$ на рис. 6 ; 3, 4 на рис. 7; 14 на рис. 8; 12 на рис. 9), что совпадает с кинематическим типом трансформных разломов [Boriskina et al., 2019]. Также на вероятное продолжение разлома Носаппу попадает гипоцентр сильнейшего землетрясения промежуточных глубин с известным механизмом очага, произошедшего 06.12.1978 г. с $M_{w}=$ =7.8, которое, судя по механизму очага, может являться левосторонним сдвигом вдоль этого трансформного разлома (см. рис. 4).

\section{5. СРАВНЕНИЕ РЕЗУЛЬТАТОВ}

Поскольку наиболее детально ориентация главных осей напряжений в двойной сейсмофокальной зоне на изучаемом участке приводится в статьях [Christova et al., 2006] для Хоккайдо и севера Хонсю и [Christova, 2015] для Курильских островов, имеет смысл провести сравнение полученных результатов с данными, опубликованными в этих статьях.

При сравнении было учтено некоторое расхождение в терминологии. В названных статьях направление главной оси максимальных сжимающих напряжений (maximum compressive stress) обозначается как $\sigma_{1}$, главная ось минимальных сжимающих напряжений соответственно $\sigma_{3}$. В настоящей работе автор следует терминологии, согласно которой алгебраически максимальное девиаторное напряжение (минимальное сжатие) соответствует удлинению материала и обозначается $\sigma_{1}$; соответственно алгебраически минимальное девиаторное напряжение (максимальное сжатие) обозначается $\sigma_{3}$.

Для удобства сопоставления на рис. 6, 7, 8, 9 были добавлены стереограммы механизмов, соответствующие ориентации осей главных напряжений по данным упомянутых статей (синие области), которые можно сравнить с результатами представленной работы, пересчитанными на поверхность Земли (механизмы с черными областями).

В работах [Christova et al., 2006; Christova, 2015] для области средних глубин вдоль всего рассматриваемого района выделяются три объема с отличными системами 
напряжений: первый в верхней части (до 60-70 км) соответствует кластерам настоящей работы, отнесенным к продолжению зоны контакта литосферных плит (2, $6,8,12,13,15,16$ на рис. $6 ; 4,6,8,9,10$ на рис. $7 ; 10,12$ на рис. 8; 2, 4, 6, 13 на рис. 9). К этому же объему отнесен весь верхний слой под о. Хоккайдо и часть нижнего слоя под Центральным Хоккайдо (3, 7 на рис. 6; 5, 6 на рис. 8).

Ориентация главных осей напряжений под центром о. Хоккайдо в верхнем слое практически идентична их ориентации в нижнем слое, что совпадает с выводами представляемой работы. В статье [Christova et al., 2006] предполагается, что это может являться результатом влияния вертикального разлома (Tokachi-Oki slab-cracking zone) и резкого изменения наклона сейсмофокальной зоны под о. Хоккайдо.

Второй объем относится непосредственно к верхнему слою двуслойной сейсмофокальной зоны, третий - к нижнему слою. Для сегментов «d», «е» в работе [Christova, 2015] приводится единое поле напряжений для обоих слоев сейсмофокальной зоны, поскольку выделить слои не удалось. Как видно из 17 на рис 6; 11 на рис. 7; 15, 16 на рис. 8; 8, 10 на рис. 9, такое осредненное поле напряжений является промежуточным между практически чистым сжатием вдоль слэба верхнего слоя и растяжением нижнего.

Для нижнего слоя под северо-восточной частью o. Хоккайдо в [Christova et al., 2006] приведено два варианта ориентации главных осей поля напряжений. В представляемой работе удалось показать, что эти варианты соответствуют двум разным пространственным областям: первый отвечает меньшим глубинам слоя (7 на рис. 8), а второй - бо́льшим (8 на рис. 8).

Можно констатировать, что для крупных групп кластеров с надежными результатами первой - второй итерации расчетов полученное поле напряжений неплохо соответствует результатам работ [Christova et al., 2006; Christova, 2015], также рассчитанным по большому числу механизмов для крупных областей $(2,3$, $4,6,8,10,12$ на рис. $6 ; 3,4,6,10,12$ на рис. 8). Расхождения в первую очередь касаются небольших групп обособленных кластеров, показывающих локальные неоднородности поля напряжений, как правило, полученных в третьей итерации расчетов $(1,9,13$ на рис. 6 ; $1,2,3,13$ на рис. $7 ; 1,8,13$ на рис. 8 и т.д.). В частности, в работах, с которыми проводится сравнение, отсутствуют области со сдвиговым типом напряженного состояния.

В целом, в более масштабных по изучаемой территории работах [Christova et al., 2006; Christova, 2015] оценки ориентации осей главных напряжений выполнены для более крупных областей по большим массивам данных, что, несомненно, придает результатам большую надежность. В представляемой работе предпринята попытка детализировать картину, что и стало главной причиной локальных отличий в результатах.

\section{6. УСТОЙЧИВОСТЬ ВО ВРЕМЕНИ}

\section{И ВЛИЯНИЕ ЗЕМЛЕТРЯСЕНИЯ ТОХОКУ 2011 Г.}

11 марта 2011 г. в Японской субдукционной области, соседней с изучаемой, произошло землетрясение магнитудой $M_{w}=9.0$. Оно существенно изменило режим сейсмического процесса в пределах верхней части японской сейсмофокальной зоны, что нашло отражение в смене кинематических типов механизмов очагов землетрясений на большой площади. Взбросовый тип механизмов в коре континентального склона сменился сбросовым. Это проявилось для глубин 0-20 км, в меньшей степени - для глубин 20-40 км и практически не проявилось для глубин более 50 км. Важно отметить то, что эти изменения продолжаются и в настоящее время, через 10 лет после мегаземлетрясения [Rebetsky, Polets, 2014, 2019].

Курило-Камчатская зона субдукции примыкает к Японской с севера. В данной работе рассматриваются промежуточные глубины землетрясений (более 50 км). Тем не менее интересно оценить влияние мегаземлетрясения на ориентацию главных осей напряжений здесь, если таковое обнаружится. Помимо этого, эксперимент позволяет оценить устойчивость поля напряжений со временем.

Эксперимент проведен по данным каталога NIED 2000-2019 гг., описанным выше и разделенным примерно пополам по дате 11 марта 2011 г. Область проведения - сегменты «а» - «d», в остальном условия повторяются.

Результаты сведены в табл. 6, 7, в которых показана ориентация главных осей тектонических напряжений по полному массиву данных и частям каталога до и после землетрясения Тохоку в тех же кластерах, что

Таблица 6. Сравнение параметров напряженного состояния южной части Курило-Камчатской зоны субдукции на промежуточных глубинах в верхнем слое до и после землетрясения Тохоку 11 марта 2011 г. на основе данных NIED 2000-2019 гг. в системе координат, связанной с поверхностью Земли

Table 6. The stress state comparison for the southern part of the Kuril-Kamchatka subduction zone at intermediate depths in the upper layer before and after the Tohoku earthquake on March 11, 2011 based on NIED 2000-2019 data in the coordinate system associated with the Earth's surface

\begin{tabular}{|c|c|c|c|c|c|c|c|c|c|c|c|}
\hline $\begin{array}{l}\text { № } \\
\text { на рис. } 6\end{array}$ & $\begin{array}{c}\text { Долгота, } \\
\text { ов.д. }\end{array}$ & $\begin{array}{l}\text { Широта, } \\
\text { ॰ с.ш. }\end{array}$ & $\begin{array}{c}\text { Глубина*, } \\
\text { км }\end{array}$ & $\mathrm{Pl}$ & $\mathrm{Az}$ & $\mathrm{Pl}$ & $\mathrm{Az}$ & $\mathrm{Pl}$ & $\mathrm{Az}$ & $\mu_{\sigma}$ & $\begin{array}{c}\text { Тип напряженного } \\
\text { состояния** }\end{array}$ \\
\hline 2 & 143.0 & 42.2 & 59 & 66 & 289 & 3 & 27 & 23 & 118 & 0.1 & вертикальный сдвиг \\
\hline До & & & & 67 & 295 & 1 & 28 & 23 & 118 & 0.0 & вертикальный сдвиг \\
\hline После & & & & 64 & 283 & 8 & 30 & 25 & 123 & 0.2 & вертикальный сдвиг \\
\hline
\end{tabular}


Таблица 6. (продолжение)

Table 6. (continued)

\begin{tabular}{|c|c|c|c|c|c|c|c|c|c|c|c|}
\hline \multirow{2}{*}{$\begin{array}{l}\text { № } \\
\text { на рис. } 6\end{array}$} & \multirow{2}{*}{$\begin{array}{c}\text { Долгота, } \\
\text { о в.д. }\end{array}$} & \multirow{2}{*}{$\begin{array}{l}\text { Широта, } \\
\text { ॰ с.ш. }\end{array}$} & \multirow{2}{*}{$\begin{array}{l}\text { Глубина*, } \\
\text { км }\end{array}$} & \multicolumn{2}{|c|}{$\sigma_{1}$} & \multicolumn{2}{|c|}{$\sigma_{2}$} & \multicolumn{2}{|c|}{$\sigma_{3}$} & \multirow{2}{*}{$\mu_{\sigma}$} & \multirow{2}{*}{$\begin{array}{c}\text { Тип напряженного } \\
\text { состояния** }\end{array}$} \\
\hline & & & & $\mathrm{Pl}$ & $\mathrm{Az}$ & $\mathrm{Pl}$ & $\mathrm{Az}$ & $\mathrm{Pl}$ & $\mathrm{Az}$ & & \\
\hline 3 & 143.2 & 42.8 & 83 & 32 & 13 & 21 & 117 & 50 & 235 & -0.5 & растяжение со сдвигом \\
\hline До & & & & 24 & 24 & 40 & 135 & 41 & 272 & -0.5 & сдвиг \\
\hline После & & & & 43 & 39 & 42 & 186 & 17 & 292 & -0.2 & растяжение со сдвигом \\
\hline 4 & 143.5 & 42.5 & 64 & 36 & 19 & 3 & 287 & 54 & 194 & -0.1 & растяжение \\
\hline До & & & & 32 & 24 & 16 & 283 & 53 & 170 & 0.0 & растяжение \\
\hline После & & & & 45 & 28 & 1 & 297 & 45 & 206 & 0.0 & растяжение \\
\hline 5 & 144.3 & 42.6 & 56 & 46 & 1 & 24 & 244 & 35 & 137 & 0.1 & растяжение \\
\hline До & & & & 53 & 340 & 21 & 220 & 29 & 118 & 0.5 & растяжение \\
\hline После & & & & 38 & 8 & 15 & 266 & 48 & 159 & 0.0 & растяжение \\
\hline 6 & 144.9 & 42.9 & 62 & 66 & 265 & 14 & 30 & 19 & 125 & 0.0 & вертикальный сдвиг \\
\hline До & & & & 66 & 265 & 14 & 30 & 19 & 125 & 0.0 & вертикальный сдвиг \\
\hline После & & & & 76 & 311 & 1 & 217 & 14 & 127 & 0.1 & вертикальный сдвиг \\
\hline 8 & 145.7 & 43.1 & 64 & 62 & 336 & 10 & 225 & 26 & 130 & 0.1 & растяжение \\
\hline До & & & & 70 & 313 & 1 & 221 & 20 & 131 & 0.0 & растяжение \\
\hline После & & & & 44 & 349 & 22 & 236 & 38 & 128 & 0.2 & растяжение \\
\hline 10 & 146.1 & 43.4 & 70 & 66 & 135 & 3 & 37 & 24 & 306 & 0.1 & сжатие \\
\hline До & & & & 58 & 150 & 12 & 40 & 29 & 303 & 0.0 & сжатие \\
\hline После & & & & 69 & 72 & 18 & 220 & 10 & 314 & 0.1 & сжатие \\
\hline 11 & 146.4 & 43.8 & 94 & 33 & 171 & 29 & 61 & 44 & 299 & 0.1 & сжатие \\
\hline До & & & & 44 & 172 & 28 & 51 & 33 & 301 & 0.1 & сжатие \\
\hline После & & & & 35 & 188 & 30 & 74 & 40 & 315 & 0.2 & сжатие \\
\hline 12 & 147.0 & 43.5 & 52 & 49 & 332 & 9 & 232 & 40 & 134 & 0.1 & растяжение \\
\hline До & & & & 55 & 328 & 1 & 59 & 35 & 150 & 0.2 & растяжение \\
\hline После & & & & 60 & 345 & 9 & 238 & 28 & 143 & -0.1 & растяжение \\
\hline 13 & 147.3 & 43.7 & 58 & 53 & 28 & 37 & 195 & 6 & 290 & -0.4 & сдвиг \\
\hline До & & & & 44 & 35 & 46 & 204 & 5 & 300 & -0.3 & сдвиг \\
\hline После & & & & 55 & 33 & 31 & 183 & 15 & 281 & -0.3 & сдвиг \\
\hline 14 & 146.9 & 44.1 & 100 & 59 & 67 & 19 & 191 & 24 & 290 & 0.3 & сжатие со сдвигом \\
\hline До & & & & 62 & 77 & 14 & 194 & 24 & 291 & 0.5 & сжатие со сдвигом \\
\hline После & & & & 57 & 75 & 20 & 197 & 26 & 297 & 0.3 & сжатие со сдвигом \\
\hline 15 & 147.8 & 43.7 & 46 & 58 & 326 & 10 & 219 & 30 & 123 & 0.2 & растяжение \\
\hline До & & & & 47 & 344 & 15 & 237 & 39 & 135 & 0.7 & растяжение \\
\hline После & & & & 54 & 360 & 21 & 238 & 28 & 137 & 0.1 & растяжение \\
\hline 16 & 148.4 & 44.1 & 52 & 54 & 340 & 21 & 219 & 28 & 118 & 0.6 & растяжение \\
\hline До & & & & 55 & 336 & 9 & 233 & 34 & 137 & 0.3 & растяжение \\
\hline После & & & & 43 & 347 & 26 & 231 & 36 & 120 & 0.7 & растяжение \\
\hline
\end{tabular}

Примечание. * - указана глубина расчетной точки на условной плоскости относительно поверхности Земли. ** - указан тип напряженного состояния кластера относительно условной плоскости.

Note. ${ }^{*}$ - depth of the computational point on the reference plane shown relative to the Earth's surface. ${ }^{* *}-$ stressed-state type of the cluster shown relative to the reference plane.

и в табл. 2, 4, с условием, что в данном кластере или ближайшем соседнем с ним для обоих временных периодов удалось получить оценку.

В связи с уменьшением объема каталогов количество кластеров, для которых удалось получить ориентацию главных осей поля напряжения, уменьшилось примерно вдвое, главным образом за счет наименее обеспеченных данными сегментов «а» и «b».

Однако при сравнении полученных результатов очевидно, что поле ориентаций главных осей напряжений очень устойчиво. Практически нигде тип напряженного состояния в кластере не изменился. Некоторые вариации в ориентации осей главных напряжений наблюдаются. Это может оказаться следствием уменьшения объема выборки и попадания в нее более далеких землетрясений из-за увеличенной области осреднения. Тем не менее в вариациях ориентации осей не просматривается общей системы.

Можно сделать вывод, что землетрясение Тохоку значимым образом не повлияло на ориентацию главных 
Таблица 7. Сравнение параметров напряженного состояния южной части Курило-Камчатской зоны субдукции на промежуточных глубинах в нижнем слое до и после землетрясения Тохоку 11 марта 2011 г. на основе данных NIED 2000-2019 гг. в системе координат, связанной с поверхностью Земли

Table 7. The stress state comparison for the southern part of the Kuril-Kamchatka subduction zone at intermediate depths in the lower layer before and after the Tohoku earthquake on March 11, 2011 based on NIED 2000-2019 data in the coordinate system associated with the Earth's surface

\begin{tabular}{|c|c|c|c|c|c|c|c|c|c|c|c|}
\hline $\begin{array}{l}\text { № } \\
\text { на рис. } 8\end{array}$ & $\begin{array}{c}\text { Долгота, } \\
{ }^{\circ} \text { в.д. }\end{array}$ & $\begin{array}{l}\text { Широта, } \\
\text { ॰ с.ш. }\end{array}$ & $\begin{array}{l}\text { Глубина*, } \\
\text { км }\end{array}$ & $\mathrm{Pl}$ & $\mathrm{Az}$ & $\mathrm{Pl}$ & $\mathrm{Az}$ & $\mathrm{Pl}$ & $\mathrm{Az}$ & $\mu_{\sigma}$ & $\begin{array}{c}\text { Тип напряженного } \\
\text { состояния** }\end{array}$ \\
\hline 7 & 145.3 & 43.0 & 78 & 40 & 336 & 33 & 213 & 32 & 98 & -0.2 & растяжение со сдвигом \\
\hline До & & & & 31 & 0 & 40 & 239 & 34 & 114 & -0.2 & растяжение \\
\hline После & & & & 64 & 16 & 3 & 280 & 26 & 189 & 0.3 & растяжение \\
\hline 9 & 145.9 & 43.1 & 80 & 33 & 351 & 15 & 251 & 52 & 140 & 0.0 & растяжение \\
\hline До & & & & 32 & 345 & 23 & 240 & 49 & 121 & 0.0 & растяжение \\
\hline После & & & & 35 & 351 & 10 & 254 & 53 & 150 & 0.0 & растяжение \\
\hline 10 & 146.7 & 43.1 & 56 & 63 & 355 & 19 & 221 & 18 & 125 & 0.2 & растяжение \\
\hline До & & & & 58 & 351 & 16 & 234 & 27 & 136 & 0.0 & растяжение \\
\hline После & & & & 44 & 352 & 20 & 241 & 39 & 135 & 0.4 & растяжение \\
\hline 12 & 147.3 & 43.3 & 56 & 64 & 355 & 21 & 216 & 16 & 120 & 0.0 & растяжение \\
\hline До & & & & 64 & 11 & 24 & 217 & 10 & 122 & 0.0 & растяжение \\
\hline После & & & & 58 & 346 & 16 & 228 & 26 & 130 & 0.0 & растяжение \\
\hline 16 & 147.3 & 44.0 & 104 & 31 & 329 & 4 & 236 & 58 & 140 & -0.2 & растяжение \\
\hline До & & & & 19 & 339 & 3 & 70 & 71 & 168 & 0.2 & растяжение \\
\hline После & & & & 17 & 6 & 64 & 237 & 19 & 102 & 0.0 & растяжение со сдвигом \\
\hline 17 & 147.8 & 43.7 & 68 & 33 & 1 & 26 & 253 & 46 & 133 & -0.1 & растяжение \\
\hline До & & & & 38 & 359 & 28 & 243 & 39 & 128 & 0.0 & растяжение \\
\hline После & & & & 38 & 359 & 28 & 243 & 39 & 128 & -0.1 & растяжение \\
\hline 18 & 148.0 & 44.0 & 86 & 26 & 324 & 8 & 230 & 63 & 124 & 0.4 & растяжение \\
\hline До & & & & 22 & 300 & 11 & 35 & 65 & 150 & 0.6 & растяжение \\
\hline После & & & & 32 & 312 & 3 & 44 & 58 & 139 & 0.2 & растяжение \\
\hline
\end{tabular}

Примечание. * - указана глубина расчетной точки на условной плоскости относительно поверхности Земли. ${ }^{*}$ - указан тип напряженного состояния кластера относительно условной плоскости.

Note. ${ }^{*}$ - depth of the computational point on the reference plane shown relative to the Earth's surface. ${ }^{* *}-$ stressed-state type of the cluster shown relative to the reference plane.

осей тектонических напряжений внутри субдуцирующей плиты на интервале промежуточных глубин землетрясений южного фланга Курило-Камчатской сейсмофокальной зоны.

\section{7. ЗАКЛЮЧЕНИЕ}

Проведена детальная реконструкция поля ориентации главных осей тектонических напряжений сейсмоактивной части погружающейся Тихоокеанской литосферной плиты на участке промежуточных глубин землетрясений южного фланга Курило-Камчатской субдукционной системы отдельно вдоль верхнего и нижнего слоя двойной сейсмофокальной зоны.

Для этого привлечены данные двух каталогов механизмов (тензоров сейсмического момента) землетрясений, из которых выделены по каждому каталогу выборки для верхнего и нижнего слоя на глубинах 50250 км, частично пересекающиеся в двух из шести принятых для расчета сегментах.

Проведена инверсия поля напряжений по механизмам очагов землетрясений полученных каталогов, использовался итерационный подход с уменьшением размера выборки и увеличением области осреднения, что позволяет максимально детализировать результат в тех областях, где наблюдается избыток данных, и получить оценочные результаты там, где данных для анализа недостаточно.

Результаты расчетов представлены в виде схем напряженного состояния изучаемых областей в расчетных кластерах в пределах условных плоскостей сегментов, совмещенных на рис. 6, 7, 8, 9. Для некоторых кластеров, наиболее характерных для крупной группы, построена стереографическая проекция положения главных осей напряжений на условную плоскость (в виде механизма очага с зелеными областями волн сжатия), на поверхность Земли (с черными областями). Параметры главных осей напряжений в выбранных кластерах, пересчитанные для удобства использования в традиционную систему координат, связанную с поверхностью Земли, представлены в виде таблиц (см. табл. 2, 3, 4, 5).

Полученный результат в целом согласуется с гипотезами образования двухслойной зоны субдукции на промежуточных глубинах: подтверждено преобладание 
наибольшего сжатия вдоль слэба в верхнем слое и наименьшего сжатия вдоль слэба в нижнем под Курильскими островами. Однако направление главных осей $\sigma_{3}$ (наибольшего сжатия) и $\sigma_{1}$ (наименьшего сжатия) смещено относительно направления падения слэба: против часовой стрелки на $30-40^{\circ}$ для $\sigma_{3}$ в верхнем слое, что совпадает с направлением погружения плиты; по часовой стрелке для $\sigma_{1}$ в нижнем слое. Это может являться следствием правосторонней сдвиговой компоненты в поддвиге Тихоокеанской плиты.

Выявлены участки, находящиеся в условиях сдвиговых напряжений, самые протяженные - напротив северной части о. Кунашир и под южной частью о. Хоккайдо. Система напряжений в большинстве сдвиговых кластеров совпадает с кинематическим типом (левый сдвиг) трансформных разломов Носаппу, Итуруп, Уруп, которые предположительно остаются сейсмоактивными в погрузившейся части плиты, хотя положение кластеров с вероятным продолжением разломных зон не совпадает.

Проведенное сравнение полученных решений с результатами работ [Christova et al., 2006; Christova, 2015], также выполненных методом инверсии механизмов очагов, но в более крупном масштабе, показало хорошую сходимость для основных крупных групп кластеров. Расхождения в первую очередь касаются небольших групп обособленных кластеров, показывающих локальные неоднородности поля напряжений.

Не обнаружено влияние землетрясения Тохоку 11 марта 2011 г. на состояние поля напряжений исследуемого участка.

\section{8. БЛАГОДАРНОСТИ}

Автор благодарит Ю.Л. Ребецкого за предоставленную методику, а также выражает ему и А.В. Ландеру признательность за ценные рекомендации на этапе рецензирования статьи.

В работе применялась программа FMC [Álvarez-Gómez, 2019].

\section{9. ЛИТЕРАТУРА / REFERENCES}

Álvarez-Gómez J.A., 2019. FMC-Earthquake Focal Mechanisms Data Management, Cluster and Classification. SoftwareX 9, 299-307. https://doi.org/10.1016/j.softx.2019.03.008.

Astiz L., Lay T., Kanamori H., 1988. Large IntermediateDepth Earthquakes and the Subduction Process. Physics of the Earth and Planetary Interiors 53 (1-2), 80-166. https:// doi.org/10.1016/0031-9201(88)90138-0.

Boriskina N.G., Kasatkin S.A., Khomich V.G., 2019. Geology, Geodynamics and Noble Metals Mineralization in the Southern Flank of the Kuril Island-Arc System. Advances in Current Natural Sciences 8, 44-49 (in Russian) [Борискина Н.Г., Касаткин С.А., Хомич В.Г. Геология, геодинамика и благороднометалльное оруденение южного фланга Курильской островодужной системы // Успехи современного естествознания. 2019. № 8. С. 44-49].

Chen P.F., Bina C.R., Okal E.A., 2004. A Global Survey of Stress Orientations in Subducting Slabs as Revealed by
Intermediate-Depth Earthquakes. Geophysical Journal International 159 (2), 721-733. https: //doi.org/10.1111/j. 1365-246X.2004.02450.x.

Christova C.V., 2015. Spatial Distribution of the Contemporary Stress Field in the Kurile Wadati-Benioff Zone by Inversion of Earthquake Focal Mechanisms. Journal of Geodynamics 83, 1-17. https://doi.org/10.1016/j.jog.2014. 11.001.

Christova C., Hirata N., Kato A., 2006. Contemporary Stress Field in the Wadati-Benioff Zone at the Japan-Kurile Arc-Arc Junction (North Honshu, the Hokkaido Corner and Hokkaido Island) by Inversion of Earthquake Focal Mechanisms. Bulletin of the Earthquake Research Institute 81, 1-18.

Christova C., Tsapanos T., 2000. Depth Distribution of Stresses in the Hokkaido Wadati-Benioff Zone as Deduced by Inversion of Earthquake Focal Mechanisms. Journal of Geodynamics 30 (5), 557-573. https://doi.org/10.1016/ S0264-3707(00)00009-0.

Faccenda M., Gerya T.V., Mancktelow N.S., Moresi L., 2012. Fluid Flow during Slab Unbending and Dehydration: Implications for Intermediate-Depth Seismicity, Slab Weakening and Deep Water Recycling. Geochemistry, Geophysics, Geosystems 13 (1). https://doi.org/10.1029/20 11GC003860.

Fujita K., Kanamori H., 1981. Double Seismic Zones and Stresses of Intermediate Depth Earthquakes. Geophysical Journal International 66 (1), 131-156. https://doi.org/10. 1111/j.1365-246X.1981.tb05950.x.

Gephart J.W., Forsyth D.W., 1984. An Improved Method for Determining the Regional Stress Tensor Using Earthquake Focal Mechanism Data: Application to the San Fernando Earthquake Sequence. Journal of Geophysical Research: Solid Earth 89 (B11), 9305-9320. https://doi.org/10.1029/JB0 89iB11p09305.

Ghimire S., Kasahara M., 2009. Spatial Variation in Seismotectonics and Stress Conditions across the Kurile and Japan Trenches Inferred from the Analysis of Focal Mechanism Data in Hokkaido, Northern Japan. Journal of Geodynamics 47 (2-3), 153-166. https://doi.org/10.1016/j.jog. 2008.07.007.

Global CMT Catalog, 2020. Available from: https://www. globalcmt.org/CMTsearch.html (Last accessed November 16, 2020).

Hasegawa A., Umino N., Takagi A., 1978. Double-Planed Structure of the Deep Seismic Zone in the Northeastern Japan Arc. Tectonophysics 47 (1-2), 43-58. https://doi.org/ 10.1016/0040-1951(78)90150-6.

Hayes G.P., Moore G.L., Portner D.E., Hearne M., Flamme H., Furtney M., Smoczyk G.M., 2018. Slab2, a Comprehensive Subduction Zone Geometry Model. Science 362 (6410), 5861. https://doi.org/10.1126/science.aat4723.

Jiao W., Silver P.G., Fei Y., Prewitt C.T., 2000. Do Intermediate-and Deep-Focus Earthquakes Occur on Preexisting Weak Zones? An Examination of the Tonga Subduction Zone. Journal of Geophysical Research: Solid Earth 105 (B12), 28125-28138. https://doi.org/10.1029/2000JB 900314. 
Kasahara J., Sato T., Mochizuki K., Kobayashi K., 1997. Paleotectonic Structures and Their Influence on Recent Seismo-Tectonics in the South Kuril Subduction Zone. Island Arc 6 (3), 267-280. https://doi.org/10.1111/j.1440-1738.19 97.tb00177.x.

Kasahara M., Sasatani T., 1985. Source Characteristics of the Kunashiri Strait Earthquake of December 6, 1978 as Deduced from Strain Seismograms. Physics of the Earth and Planetary Interiors 37 (2-3), 124-134. https://doi.org/10. 1016/0031-9201(85)90046-9.

Katsumata K., Wada N., Kasahara M., 2003. Newly Imaged Shape of the Deep Seismic Zone within the Subducting Pacific Plate beneath the Hokkaido Corner, Japan-Kurile ArcArc Junction. Journal of Geophysical Research: Solid Earth 108 (B12). https://doi.org/10.1029/2002JB002175.

Kirby S.H., Durham W.B., Stern L.A., 1991. Mantle Phase Changes and Deep-Earthquake Faulting in Subducting Lithosphere. Science 252 (5003), 216-225. https://doi.org/10. 1126/science.252.5003.216.

Lay T., Ammon C.J., Kanamori H., Kim M.J., Xue L., 2011. Outer Trench-Slope Faulting and the $2011 \mathrm{M}_{\mathrm{w}} 9.0$ off the Pacific Coast of Tohoku Earthquake. Earth, Planets and Space 63 (37), 713-718. https://doi.org/10.5047/eps.2011.05.006.

NIED F-net Broadband Seismograph Network, 2020. Available from: http://www.fnet.bosai.go.jp (Last accessed November 16, 2020).

Ozel N., Moriya T., 1999. Different Stress Directions in the Aftershock Focal Mechanisms of the Kushiro-Oki Earthquake of Jan. 15, 1993, SE Hokkaido, Japan, and Horizontal Rupture in the Double Seismic Zone. Tectonophysics 313 (3), 307-327. https://doi.org/10.1016/S0040-1951(99) 00207-3.

Polets A.Yu., 2018. The Stress-Strained State of Zones of Deep-Focus Earthquakes of the Japan Sea Region. Geosystems of Transition Zones 2 (4), 302-311 (in Russian) [Полец А.Ю. Напряженно-деформированное состояние зоны глубокофокусных землетрясений региона Японского моря // Геосистемы переходных зон. 2018. Т. 2. № 4. C. 302-311]. http://dx.doi.org/10.30730/2541-8912. 2018.2.4.302-311.

Poplavskaya L.N., Rudik M.I., Nagornykh T.V., Safonov D.A., 2011. Catalogue of Focal Mechanisms of Strong $(M \geq 6.0)$ Earthquakes in the Kuril-Okhotsk Region of 1964-2009. Dal'nauka, Vladivostok, 131 p. (in Russian) [Поплавская Л.Н., Рудик М.И., Нагорных Т.В., Сафонов Д.А. Каталог механизмов очагов сильных $(M \geq 6.0)$ землетрясений Курило-Охотского региона 1964-2009 гг. Владивосток: Дальнаука, 2011. 131 с.].

Prytkov A.S., Vasilenko N.F., Frolov D.I., 2017. Recent Geodynamics of the Kuril Subduction Zone. Russian Journal of Pacific Geology 11, 19-24. https://doi.org/10.1134/S1 819714017010067.

Rebetsky Yu.L., 1999. Methods for Reconstructing Tectonic Stresses and Seismotectonic Deformations Based on the Modern Theory of Plasticity. Doklady Earth Sciences 365 (3), 370-373.

Rebetsky Yu.L., 2003. Development of the Cataclastic Analysis Method of Slip Faults for Tectonic Stress Estimation.
Doklady Earth Sciences 388 (2), 237-241 (in Russian) [Peбецкий Ю.Л. Развитие метода катакластического анализа сколов для оценки величин тектонических напряжений // Доклады Академии наук 388 (2), С. 237-241].

Rebetsky Yu.L., 2007. Tectonic Stresses and Strength of Mountain Ranges. Nauka, Moscow, 406 p. (in Russian) [Peбецкий Ю.Л. Тектонические напряжения и прочность горных массивов. М.: Наука, 2007. 406 с.].

Rebetsky Yu.L., Polets A.Yu., 2014. The State of Stresses of the Lithosphere of Japan before the Catastrophic Tohoku Earthquake of 11 March 2011. Geodynamics \& Tectonophysics 5 (2), 469-506 (in Russian) [Ребецкий Ю.Л., Полец А.Ю. Напряженное состояние литосферы Японии перед катастрофическим землетрясением Тохоку 11.03.2011 // Геодинамика и тектонофизика. 2014. Т. 5. № 2. С. 469506]. https://doi.org/10.5800/GT-2014-5-2-0137.

Rebetsky Yu.L., Polets A.Yu., 2019. The State of Stress in the Aftershock Area of the March 11, 2011 Tohoku Earthquake. In: Geodynamical Processes and Natural Hazards. Proceedings of the III National Scientific Conference with Foreign Participants (May 27-31, 2019, Yuzhno-Sakhalinsk). IOP Conference Series: Earth and Environmental Science 324, 012005. http://dx.doi.org/10.1088/1755-1315/32 4/1/012005.

Rodkin M.V., Rundkvist D.V., 2017. Geofluid Geodynamics. Application to Seismology, Tectonics, Ore and Oil Genesis Processes. Intellect, Dolgoprudny, 288 p. (in Russian) [Родкин М.В., Рундквист Д.В. Геофлюидогеодинамика. Приложение к сейсмологии, тектонике, процессам рудо- и нефтегенеза. Долгопрудный: Интеллект, 2017. 288 c.].

Safonov D.A., 2019. Spatial Distribution of Tectonic Stress in the Southern Deep Part of the Kuril-Kamchatka Subduction Zone. Geosystems of Transition Zones 3 (2), 175-188 (in Russian] [Сафонов Д.А. Пространственное распределение тектонических напряжений в южной глубокой части Курило-Камчатской зоны субдукции // Геосистемы переходных зон. 2019. Т. 3. № 2. C. 175-188]. http://dx. doi.org/10.30730/2541-8912.2019.3.2.175-188.

Safonov D.A., 2020. Reconstruction of the Tectonic Stress Field in the Deep Parts of the Southern Kuril-Kamchatka and Northern Japan Subduction Zones. Geodynamics \& Tectonophysics 11 (4), 743-755 (in Russian) [Сафонов Д.А. Реконструкция поля тектонических напряжений глубокой части южного сегмента Курило-Камчатской и северного сегмента Японской зоны субдукции // Геодинамика и тектонофизика. 2020. Т. 11. № 4. С. 743755]. https://doi.org/10.5800/GT-2020-11-4-0504.

Safonov D.A., Konovalov A.V., Zlobin T.K., 2015. The Urup Earthquake Sequence of 2012-2013. Journal of Volcanology and Seismology 9, 402-411. https://doi.org/10.1134/ S074204631506007X.

Seliverstov N.I., 2007. Structure of Kamchatka SeismoFocal Zone. Bulletin of Kamchatka Regional Association "Educational-Scientific Center". Earth Sciences 1 (9), 10-26 (in Russian] [Селивёрстов Н.И. Структура сейсмофокальной зоны Камчатки // Вестник КРАУНЦ. Серия: Науки о Земле. 2007. Вып. 9. № 1. С. 10-26]. 
Sykes L.R., 1966. The Seismicity and Deep Structure of Island Arcs. Journal of Geophysical Research 71 (12), 29813006. https://doi.org/10.1029/JZ071i012p02981.

Terakawa T., Matsu'ura M., 2010. The 3-D Tectonic Stress Fields in and around Japan Inverted from Centroid Moment Tensor Data of Seismic Events. Tectonics 29 (6). https:// doi.org/10.1029/2009TC002626.

Tikhonov I.N., Shevchenko G.V. (Eds), 2015. Shikotan Earthquake and Tsunami of October 4(5), 1994. Chronicle Events, Impact Analysis and Current State of the Problem.
Collection of Articles. IMGG FEB RAS, Yuzhno-Sakhalinsk, 128 p. (in Russian) [Шикотанское землетрясение и цунами 4(5) октября 1994 года // Хроника событий, анализ последствий и современное состояние проблемы: Сборник статей / Ред. И.Н. Тихонов, Г.В. Шевченко. Южно-Сахалинск: ИМГиГ ДВО РАН, 2015. 128 с.].

Zlobin T.K., Safonov D.A., Polets A.Yu., 2011. Distribution of Earthquakes by the Types of the Source Motions in the Kuril-Okhotsk Region. Doklady Earth Sciences 440, 14101412. https://doi.org/10.1134/S1028334X11100096. 